\title{
TRP Vanilloid 2 Knock-Out Mice Are Susceptible to Perinatal Lethality But Display Normal Thermal and Mechanical Nociception
}

\author{
Una Park, ${ }^{1}$ Nisha Vastani, ${ }^{3}$ Yun Guan, ${ }^{2}$ Srinivasa N. Raja, ${ }^{2}$ Martin Koltzenburg, ${ }^{3}$ and Michael J. Caterina ${ }^{1}$ \\ ${ }^{1}$ Departments of Biological Chemistry and Neuroscience, Center for Sensory Biology and ${ }^{2}$ Department of Anesthesiology and Critical Care Medicine, Johns \\ Hopkins University School of Medicine, Baltimore, Maryland 21205, and ${ }^{3}$ UCL Institute of Neurology, Medical Research Council Centre for Neuromuscular \\ Diseases, UCL, London, United Kingdom WC1N 3BG
}

TRP vanilloid 2 (TRPV2) is a nonselective cation channel expressed prominently in medium- to large-diameter sensory neurons that can be activated by extreme heat $\left(>52^{\circ} \mathrm{C}\right)$. These features suggest that TRPV2 might be a transducer of noxious heat in vivo. TRPV2 can also be activated by hypoosmolarity or cell stretch, suggesting potential roles in mechanotransduction. To address the physiological functions of TRPV2 in somatosensation, we generated TRPV2 knock-out mice and examined their behavioral and electrophysiological responses to heat and mechanical stimuli. TRPV2 knock-out mice showed reduced embryonic weight and perinatal viability. As adults, surviving knock-out mice also exhibited a slightly reduced body weight. TRPV2 knock-out mice showed normal behavioral responses to noxious heat over a broad range of temperatures and normal responses to punctate mechanical stimuli, both in the basal state and under hyperalgesic conditions such as peripheral inflammation and L5 spinal nerve ligation. Moreover, behavioral assays of TRPV1/TRPV2 double knock-out mice or of TRPV2 knock-out mice treated with resiniferatoxin to desensitize TRPV1-expressing afferents revealed no thermosensory consequences of TRPV2 absence. In line with behavioral findings, electrophysiological recordings from skin afferents showed that $\mathrm{C}$-fiber responses to heat and $\mathrm{C}$ - and $\mathrm{A} \delta$-fiber responses to noxious mechanical stimuli were unimpaired in the absence of TRPV2. The prevalence of thermosensitive A $\delta$-fibers was too low to permit comparison between genotypes. Thus, TRPV 2 is important for perinatal viability but is not essential for heat or mechanical nociception or hypersensitivity in the adult mouse.

\section{Introduction}

Thermosensation is critical to survival. One mediator of mammalian thermosensation is the capsaicin receptor, transient receptor potential vanilloid 1 (TRPV1). This nonselective cation channel can be activated by temperatures $>42^{\circ} \mathrm{C}$ and is expressed in a subset of small- to medium-diameter nociceptive neurons (Caterina et al., 1997). TRPV1 gene disruption in mice results in nearly complete ablation of heat-evoked currents in cultured

Received March 22, 2009; revised June 6, 2011; accepted June 10, 2011.

Author contributions: U.P., N.V., Y.G., S.N.R., M.K., and M.J.C. designed research; U.P., N.V., Y.G., M.K., and M.J.C. performed research; U.P., N.V., Y.G., S.N.R., M.K., and M.J.C. analyzed data; U.P., N.V., Y.G., S.N.R., M.K., and M.J.C. wrote the paper.

This work was supported by NINDS Grant R01 NS051551 (M.J.C.) and grants from the Medical Research Council and Biotechnology and Biological Sciences Research Council (M.K.). We thank David Julius, Kimberly Simpson, Kogo Takamiya, and the Johns Hopkins Transgenic Core Facility for assistance with targeting construct generation and ES cell targeting, David Ginty for the loxP-frt-Neo cassette construct, Randall Reed for CMV-Cre mice, Xinzhong Dong for mrgD-GFP mice, Allan Basbaum for antibodies, Juan Wang, John Barrett, and Xiaoxin Li for expert technical assistance, Hyosang Lee for assistance with immunoblots, Jill Brederson and Tohko lida for assistance with calcium imaging, and Jasenka Borzan, David Ginty, Xinzhong Dong, Richard Meyer, and members of Caterina laboratory for helpful suggestions and critical reading of this manuscript.

Under a licensing agreement between Merck and University of California at San Francisco, M.J.C. is entitled to a share of royalty received on sales of products used in this study. M.J.C. also serves on the Scientific Advisory Board for Hydra Biosciences, which develops products related to TRP channels. The terms of these arrangements are being managed by the Johns Hopkins University in accordance with its conflict of interest policies.

Correspondence should be addressed to Michael J. Caterina, Biophysics Building, Room 408, 725 N. Wolfe Street, Baltimore, MD 21205. E-mail: caterina@jhmi.edu.

DOI:10.1523/JNEUROSCI.1384-09.2011

Copyright $\odot 2011$ the authors $\quad 0270-6474 / 11 / 3111425-12 \$ 15.00 / 0$ dorsal root ganglion (DRG) neurons (Caterina et al., 2000; Davis et al., 2000) and decreased acute behavioral heat nociception and inflammatory thermal hyperalgesia (Caterina et al., 2000). However, TRPV1 knock-out (KO) mice exhibit residual heat-evoked behavior and normal neuropathic thermal hyperalgesia (Caterina et al., 2000; Davis et al., 2000). These findings have been corroborated by in vitro recording from skin afferents (Caterina et al., 2000; Woodbury et al., 2004; Zimmermann et al., 2005; Lawson et al., 2008) or DRG neurons (Caterina et al., 2000) and pharmacologically in wild-type (WT) mice and rats (GarcíaMartinez et al., 2002; Gavva et al., 2005) and reveal the existence of TRPV1-dependent and -independent mechanisms for heat transduction.

One of the candidate mediators of TRPV1-independent heat sensitivity is TRPV2 (VRL-1, GRC) (Caterina et al., 1999; Kanzaki et al., 1999). This channel is activated by very high temperatures $\left(>52^{\circ} \mathrm{C}\right)$ and is strongly expressed in a subpopulation of medium- to large-diameter myelinated sensory neurons. TRPV2 also exhibits broad expression in organs such as brain, spleen, and lung and participates in macrophage migration, phagocytosis, and cytokine release (Nagasawa et al., 2007; Link et al., 2010; Yamashiro et al., 2010). Besides heat, recombinant TRPV2 can be activated by hypoosmolarity (Muraki et al., 2003) or cell stretch (Iwata et al., 2003). One recent study reported a role for TRPV2 in mechanically evoked neurite outgrowth (Shibasaki et al., 2010). Several chemical stimuli, including 2-aminoethoxydiphenyl bo- 
rate (2-APB) (Hu et al., 2004), cannabinoids (Neeper et al., 2007; Qin et al., 2008; Link et al., 2010), and probenecid (Bang et al., 2007), also activate TRPV2. Phosphatidylinositol 3 (PI3) kinase signaling promotes TRPV2 activation and/or translocation to the cell surface (Kanzaki et al., 1999; Juvin et al., 2007; Link et al., 2010), yet TRPV2-specific agonists have not been reported.

TRPV2-like high-threshold heat responses have been observed in several electrophysiological settings. In primates, whereas C-fiber and type II A-fiber nociceptors are activated with a threshold of $\sim 43^{\circ} \mathrm{C}$, type I A-fiber nociceptors exhibit a much higher threshold $\left(\sim 53^{\circ} \mathrm{C}\right)$ and are sensitized by repetitive heating, similar to recombinant TRPV2 (Dubner et al., 1977; Treede et al., 1995). Heatsensitive, capsaicin-insensitive DRG neurons with thresholds $>50^{\circ} \mathrm{C}$ have also been observed in rat and, at much lower frequency, mouse DRG cultures (Nagy and Rang, 1999; Caterina et al., 2000; Ahluwalia et al., 2002; Leffler et al., 2007; Rau et al., 2007). To directly address whether TRPV2 plays a role in detection of noxious heat or mechanical stimuli under physiological or pathological conditions in vivo, we generated TRPV2 KO mice and examined their sensitivity to noxious thermal and mechanical stimuli using an array of neurophysiological and behavioral assays.

\section{Materials and Methods}

Gene targeting and mouse generation. Unless otherwise indicated, chemicals were obtained from Sigma and cell culture and molecular biology reagents from Invitrogen. A more limited description of the generation of TRPV2 KO mice used in this study has been presented previously (Link et al., 2010). For TRPV2 gene targeting, a 6.5 kb TRPV2 genomic DNA fragment corresponding to the region to be disrupted, spanning the four exons encoding the fifth transmembrane domain, pore-loop domain, and the sixth transmembrane domain (amino acid residue 527727 of mTRPV2 protein, nucleotides 2033-2636 of mTRPV2 mRNA), was excised from a bacterial artificial chromosome clone with BstEII and subcloned between two loxP sites in a vector containing a flippase recognition target (frt) recombination site-flanked neomycin cassette (gift from David Ginty, Johns Hopkins University, Baltimore, MD). Seven kilobases upstream and $3.6 \mathrm{~kb}$ downstream genomic DNA fragments were cut with BstEII and SpeI and subcloned on either side of the loxPflanked $6.5 \mathrm{~kb}$ fragment. The resulting targeting construct was linearized and electroporated into an ES cell line generated from 12956 mice by the Johns Hopkins Transgenic Core Facility. G418- and ganciclovir-resistant clones were screened for homologous recombination by Southern blotting with probes detecting the $3^{\prime}$ homology arm and the neomycin marker. Successfully targeted, euploid ES clones were injected into the C57BL/6 blastocysts, and resulting male chimeric mice were mated with C57BL/6 WT females (The Jackson Laboratory). Germ-line transmission of the TRPV2 conditional null allele was confirmed by Southern blotting, and the heterozygous offspring (HE) were mated with CMV-Cre transgenic mice (Schwenk et al., 1995) (gift from Randall Reed, Johns Hopkins University, Baltimore, MD). The resulting pups were verified for successful TRPV2 locus disruption by Cre recombinase via Southern blot and PCR analysis. Mice heterozygous for the TRPV2 null allele were mated to each other to generate paired littermates for initial phenotypic characterization. To generate mice in the F1 hybrid background, male heterozygotes backcrossed four to nine generations onto the $129 \mathrm{S6}$ (Taconic Farms) background were mated with female heterozygotes backcrossed six to nine generations onto C57BL/6. PCR primers for genotyping were $5^{\prime}$-AACAGCAAATCCTGGAACCTCAC-3', 5'-CAGCTATCCTGAGCAGAAGAGAGC-3', and 5'-AGCATCTACCCCAACCTTCAGAC-3' , yielding PCR products of $470 \mathrm{bp}$ (WT allele) and $750 \mathrm{bp}$ (null allele). For Southern blots, a 714 bp probe corresponding to a region $3^{\prime}$ of the downstream homology arm, between SpeI and KpnI sites, was generated by PCR with primers $5^{\prime}$ GAGAAAAGCCAGGGTGGGAG-3' and 5'-ACAGGGATTGAGTGTGGGTGC-3'. This probe detected a $13 \mathrm{~kb}$ fragment of the WT allele and 6.7 $\mathrm{kb}$ fragment of the $\mathrm{KO}$ allele after KpnI digestion.

The genes encoding TRPV1 and TRPV2 are located $\sim 10 \mathrm{Mb}$ apart on chromosome 11. To generate double KO mice, we mated TRPV1 KO mice (on a C57BL/6 background) and TRPV2 heterozygote mice to generate TRPV1/TRPV2 double heterozygote mice. These double heterozygote mice were mated with WT mice, and the resulting offspring were screened by Southern blotting for the inheritance of both TRPV1 and TRPV2 null alleles, presumably as a result of meiotic recombination. The resulting double heterozygous mice were intercrossed with one another to yield experimental animals. Initial comparisons of nociceptive behaviors and complete Freund's adjuvant (CFA) hyperalgesia were made between WT, TRPV1 single KO, and TRPV1/TRPV2 double KO mice, all in this randomly mixed C57BL/6 and 129 S6 background (see Fig. 5A, B,E). For repetition of acute nociceptive behavioral analysis, we subsequently backcrossed TRPV1 ${ }^{+/-}$; TRPV2 ${ }^{+/-}$mice four generations onto each genetic background and subsequently mated them with $T R P V 1^{-/-}$mice that had also been backcrossed onto either C57BL/6 or 129 S6 backgrounds to obtain TRPV1 $1^{-/-}$; TRPV2 $2^{+/-}$mice on either background. These mice were then intercrossed to generate TRPV1 $1^{-1-}$; TRPV2 $2^{+/+}$ and TRPV1 $1^{-/-}$; TRPV2 $2^{-/-}$mice on the F1 hybrid background for analysis. Genotypes were confirmed by Southern blotting, and ablated expression of both TRPV1 and TRPV2 proteins in TRPV1/TRPV2 double KO mice was confirmed by immunohistochemical staining of DRG. Mas-related gene $\mathrm{D}(\mathrm{mrgD})$-GFP mice were generously provided by Xinzhong Dong (Johns Hopkins University, Baltimore, MD). Mice (2-6 months old) were individually housed in a room with controlled humidity and temperature with $12 \mathrm{~h} \mathrm{light/dark}$ cycles and provided water and chow ad libitum. All experiments were conducted according to the protocols approved by the Johns Hopkins Animal Care and Use Committee.

RT-PCR confirmation of TRPV2 gene disruption. Total RNA was isolated from DRG of adult mice with TRIZOL reagent (Invitrogen) according to the instructions of the manufacturer. cDNA was generated by reverse transcription in a $20 \mu \mathrm{l}$ reaction containing $1 \mu \mathrm{g}$ of cDNA, oligo-dT primer, dNTP, DTT, Rnasin (Promega), and SuperScript II RNase negative reverse transcriptase (Invitrogen) at $42^{\circ} \mathrm{C}$ for $50 \mathrm{~min}$, followed by enzyme inactivation at $70^{\circ} \mathrm{C}$ for $15 \mathrm{~min}$. cDNA was subjected to PCR using primers for glyceraldehydes 3-phosphate dehydrogenase (GAPDH), TRPV1, or TRPV2 and analyzed on agarose gels containing ethidium bromide. Templates processed without reverse transcriptase served as negative controls. All bands were of the expected size. PCR primers included the following: TRPV1, 5'-ACACCAACGTGGGCATCATC-3' (2330-2349 of mTRPV1), 5'-TGGTTAGATTCACAGCTCGCTTC-3' (2764-2786 of mTRPV1); TRPV2, 5'-ACCGCATGGTGGTTTTAG-3' (1548-1565 of mTRPV2), 5' -CGCAGCACCTGGGACAGC-3' (1891-1908 of mTRPV2, antisense), 5' -GCTGTCCCAGGTGCTGCG-3' (1891-1908 of mTRPV2, sense), 5' -GGATGGTATACCTGATGAGC-3' (2524-2543 of mTRPV2, inside the deleted region), and 5'-GCAAAATTCCCTACTCTACCCTGC-3' (2753-2776 of mTRPV2); and GAPDH, 5' - TCCACCACCCTGTTGCTGTA- 3' and 5'-ACCA CAGTCCATGCCATCAC-3' (451 bp product).

Body weight measurement. For fetal weight measurements, pregnant females were killed at embryonic day 18.5, and fetuses were collected and weighed. P0 pups were weighed on the day of birth. Genomic DNA was purified from fetal or pup tails for genotyping. To evaluate postnatal body weight gain, the first measurements of body weight started at 2.5 weeks of age when mice born from the heterozygote mating were eartagged and genotyped using tail genomic DNA. Mice were weaned at 4 weeks of age. WT and TRPV2 KO mice were weighed twice a week until 6 weeks and then once a week thereafter until 14 weeks.

Immunoblot and immunohistochemistry. For immunoblot, dorsal root and trigeminal ganglia from adult mice were collected and homogenized in M-PER mammalian protein extraction reagent according to the instructions of the manufacturer (Pierce). Proteins were resolved by SDS-PAGE and transferred to PVDF membranes, followed by immunoblotting with rabbit anti-TRPV1 (C terminus) antibody (Caterina et al., 1997) or rabbit antiTRPV2 (C terminus) antibody (Caterina et al., 1999). For immunohistochemistry, mice were transcardially perfused with PBS under deep ketamine/ xylazine anesthesia, followed by $3.7 \%$ Formalin or $4 \%$ paraformaldehyde in PBS. Dorsal root or trigeminal ganglia, skin, or spinal cord were dissected and postfixed for up to $4 \mathrm{~h}$ on ice, then cryoprotected in $30 \%$ sucrose in PBS at $4^{\circ} \mathrm{C}$ for $2-3 \mathrm{~d}$, and embedded and frozen in optical cutting medium (OCT; Ted Pella). Sixteen-micrometer-thick cryostat sections were 
blocked in 10\% normal goat serum in PBS containing 0.3\% Triton X-100 (PBST) for $1 \mathrm{~h}$, reacted with primary antibodies at $4^{\circ} \mathrm{C}$ overnight, washed, and incubated $2 \mathrm{~h}$ at room temperature with Cy3-conjugated goat anti-rabbit IgG (1:800), FITC-conjugated donkey anti-mouse IgG1 (1:200), or Cy2-conjugated goat anti-mouse IgG (1:500; all from Jackson ImmunoResearch) or with Alexa Fluor 488-conjugated goat antichicken IgG (1:400; Invitrogen). After washing, dehydration, and mounting, sections were imaged using a 510 Meta confocal microscope (Carl Zeiss) or epifluorescence microscope (Nikon). Primary antibodies included rabbit anti-TRPV1 [1:1000 (Caterina et al., 1997 or Calbiochem)], rabbit anti-TRPV2 [1:100 to $1: 1000$ (Caterina et al., 1999)], mouse anti-NF52 (1:400; Sigma), rabbit anti-NF200 (1:500; Millipore Bioscience Research Reagents), guinea pig anti-calcitonin gene-related peptide (CGRP) (1:400; Peninsula/Bachem), FITC-conjugated isolectin B4 (IB4) ( $5 \mu \mathrm{g} / \mathrm{ml}$; Sigma), guinea pig anti-PKC $\gamma$ (1:1000; gift from Allan Basbaum, University of California, San Francisco, CA), mouse antiNeuN (1:200; Millipore Bioscience Research Reagents), and chicken anti-GFP (1:1000; Aves). Analysis of immunostaining was performed blinded to genotype. For marker prevalence analysis, at least 1000 neurons were scored from nonadjacent L4 and L5 DRG sections from three to seven mice per genotype. For quantification of TRPV2 immunostaining, nonadjacent L4 and L5 DRG sections double stained with anti-NeuN and anti-TRPV2 were photographed at uniform exposure for each marker. Minimum diameters of cell soma profiles $(>300$ cells per mouse) were measured in the NeuN image using NIH Image J software. Only neurons with a visible nucleus were scored. Mean intensity of TRPV2 immunoreactivity in each cell was also measured under uniform conditions using NIH Image J. Cells exhibiting strong TRPV2 staining only on the periphery were scored manually and excluded from densitometric analysis. For the remaining cells, the threshold for TRPV2 immunoreactivity was defined as 3 SDs above the mean value measured in TRPV2 KO sections. Low expressors were defined as exhibiting onefold to twofold threshold, whereas high expressors were defined as exhibiting more than twofold threshold staining.

Acute nociception assays. Before any of the behavioral assays, mice were habituated in the testing environments for at least $1 \mathrm{~h}$. All behavioral assays were performed blinded to genotype. Mechanical sensitivity was tested using calibrated von Frey filaments exerting bending forces between 0.07 and $4 \mathrm{~g}$. Each filament was gently applied for $2-3 \mathrm{~s}$ to the glabrous skin of the hindpaw of a mouse standing on a metal mesh. Each filament was applied five to eight times with at least $10 \mathrm{~min}$ between trials, and the frequency of withdrawal responses was scored at each force. Thermal sensitivity was examined using the tail-immersion, radiant paw-heating, and hotplate assays. In the tail-immersion assay, the tail of a gently restrained mouse was immersed in a water bath held at a certain temperature $\left(48-56^{\circ} \mathrm{C}\right)$, and the latency to tail flick recorded. For the radiant paw-heating assay, a radiant heat source with variable intensity was focused on the glabrous hindpaw skin of a mouse standing on the glass plate, and latency to paw withdrawal was measured. The hotplate assay measured the latency to nociceptive behaviors (shaking or licking of the hindpaw, jumping) of a mouse placed on a metal surface preheated to a fixed temperature $\left(52.5-58^{\circ} \mathrm{C}\right)$. For all three thermal nociception assays, mice were tested with at least $10 \mathrm{~min}$ interval between trials to prevent sensitization attributable to the test stimuli. In the Formalin assay, mice were subcutaneously injected with $20 \mu \mathrm{l}$ of Formalin solution (1.2\% in saline), and time spent biting or licking the injected paw was recorded over $5 \mathrm{~min}$ intervals for $45 \mathrm{~min}$. In the capsaicin eye-wipe test, a drop of capsaicin ( $0.5 \mathrm{~mm}$ in saline) was applied to the cornea, and the number of eye wipes was counted over the ensuing $5 \mathrm{~min}$.

Assays of inflammatory and neuropathic hyperalgesia. Tissue inflammation was induced by subcutaneous injection of $20 \mu \mathrm{l}$ of CFA (Sigma) into a hindpaw using a Hamilton syringe (VWR). Thermal and mechanical hypersensitivity induced in the inflammation was measured using radiant paw-heating and von Frey filaments, respectively, before injection and at 24 and $48 \mathrm{~h}$ after injection. Neuropathic hyperalgesia was introduced by unilateral injury of an L5 spinal nerve. The left L5 spinal nerve was exposed in a mouse deeply anesthetized with Nembutal, tightly ligated with 9-0 silk, and then cut distal to the ligation. Muscle was sutured with 6-0 chromic gut, and skin was stapled. Mechanical and thermal responsiveness was measured before surgery and at the indicated number of days after surgery using von Frey filaments and the radiant pawheating assay, respectively (Guan et al., 2008).

Resiniferatoxin-mediated desensitization. Mice were injected with buprenorphine $(0.45 \mathrm{mg} / \mathrm{kg}$, s.c.). Thirty minutes later, resiniferatoxin (RTX) $(10 \mu \mathrm{g} / \mathrm{kg}$; Sigma) or vehicle (10\% ethanol, $5 \%$ Tween 80 , and $85 \%$ saline) was injected subcutaneously into the skin of the upper back. RTX-injected mice became transiently hypoactive but recovered their normal level of activity within $2-3 \mathrm{~d}$. Animals that failed to recover within $3 \mathrm{~d}$ were killed by $\mathrm{CO}_{2}$ asphyxiation. A second RTX injection was performed $7 \mathrm{~d}$ after the first. Thermal sensitivity was measured using the radiant paw-heating assay before and beginning at $4 \mathrm{~d}$ after the second RTX treatment. After completion of behavioral assays, desensitization of TRPV1-positive afferents was independently evaluated by hypothermic responses to injection of capsaicin $(9.8 \mu \mathrm{mol} / \mathrm{kg}$, s.c.) versus vehicle ( $10 \%$ ethanol, $10 \%$ Tween 80 , and $80 \%$ saline). Core body temperature was measured using a lubricated rectal probe.

Skin-nerve preparation and neurophysiological recording techniques. We used an ex vivo skin-nerve preparation of the mouse as described previously (Koltzenburg et al., 1997; Stucky and Koltzenburg, 1997). Briefly, we dissected the hairy skin of the hindlimb together with the saphenous nerve or the glabrous skin of the hindpaw with the tibial nerve attached and placed them corium-side up in an organ bath that was superfused with modified oxygen-saturated, synthetic interstitial fluid (SIF) containing the following (in $\mathrm{mm}$ ): $123 \mathrm{NaCl}, 3.5 \mathrm{KCl}, 0.7 \mathrm{MgSO}_{4}$, $1.7 \mathrm{NaH}_{2} \mathrm{PO}_{4}, 2.0 \mathrm{CaCl}_{2}, 9.5$ sodium gluconate, 5.5 glucose, 7.5 sucrose, and 10 HEPES, pH $7.40 \pm 0.05$ (at $32 \pm 0.5^{\circ} \mathrm{C}$ ). Single afferent fibers were recorded extracellularly from the desheathed nerve using gold wire electrodes, a custom-made low-noise differential amplifier, $100 \mathrm{~Hz} \mathrm{high-pass}$ and $1 \mathrm{kHz}$ low-pass filters, and a Micro1401 interface with Spike6 software and custom-made macros (Cambridge Electronic Design) running on a personal computer. The receptive fields of single units were identified with a manual mechanical search stimulus that exerts a force exceeding $500 \mathrm{mN}$. The software package allowed construction of peristimulus histograms and a standard quantitative analysis of stimulus intensity and unitary action potentials. The conduction velocity of each unit was determined by electrical stimulation of the receptive field with suprathreshold 0.1- to 1-ms-long square-wave pulses using a $\mathrm{Ag} / \mathrm{AgCl}$ cathode with the anode placed nearby in the organ bath. Units conducting slower than $1.2 \mathrm{~m} / \mathrm{s}$ were classified as unmyelinated (C) fibers, units conducting between 1.2 and $10 \mathrm{~m} / \mathrm{s}$ as thin myelinated $(\mathrm{A} \delta$ ) fibers, and units conducting in excess of $10 \mathrm{~m} / \mathrm{s}$ as large myelinated $(A \beta)$ units.

Skin-nerve preparation mechanical and thermal stimulation. The mechanical threshold of each unit was determined with calibrated von Frey filaments (OptiHair 2; MARSTOCKnervtest) with round tip diameters of $0.3-0.4 \mathrm{~mm}$ and bending forces ranging from 0.25 to $512 \mathrm{mN}$. Constant-force stimuli were applied when possible (but not in all units) using a custom-made feedback-controlled probe (Ostermeier-Elektronik) with a tip diameter of $0.8 \mathrm{~mm}$ placed perpendicularly onto the most sensitive spot of the receptive field. Each stimulus began with an adaptation period of $5 \mathrm{~s}$ at a force of $1 \mathrm{mN}$, and the force rose from the adaptation baseline to a preset force of $200 \mathrm{mN}$ in $20 \mathrm{~s}$

After mechanical stimulation, the receptive field was isolated with a small self-sealing metal ring ( $6 \mathrm{~mm}$ diameter), and a thermocouple was gently applied to the center of the chamber formed by the ring to measure intracutaneous temperature. The bath solution within the ring was manually removed with a syringe before the start of the cold or heat stimulus. For cold stimulation, intracutaneous temperature was lowered to $\sim 4^{\circ} \mathrm{C}$. This was done by instillation of chilled SIF by a roller pump into the small separate chamber formed by the metal ring. By manually adjusting the flow rate, an almost linear cold ramp was achieved over $30 \mathrm{~s}$ from 32 to $4^{\circ} \mathrm{C}$. Recovery to the ambient temperature of the organ bath was achieved by passive rewarming.

Heat stimuli were delivered to the epidermal side of the preparation through the translucent bottom of the organ bath using a halogen bulb focused onto the receptive field. In ramp mode, skin temperature was increased linearly within $15 \mathrm{~s}$ from 32 to $47^{\circ} \mathrm{C}$ (measured at the corium side), at a rate of $1^{\circ} \mathrm{C} / \mathrm{s}$. In plateau mode, the temperature was raised from $32^{\circ} \mathrm{C}$ to a constant temperature at $50^{\circ} \mathrm{C}$ for up to $30 \mathrm{~s}$. 
A

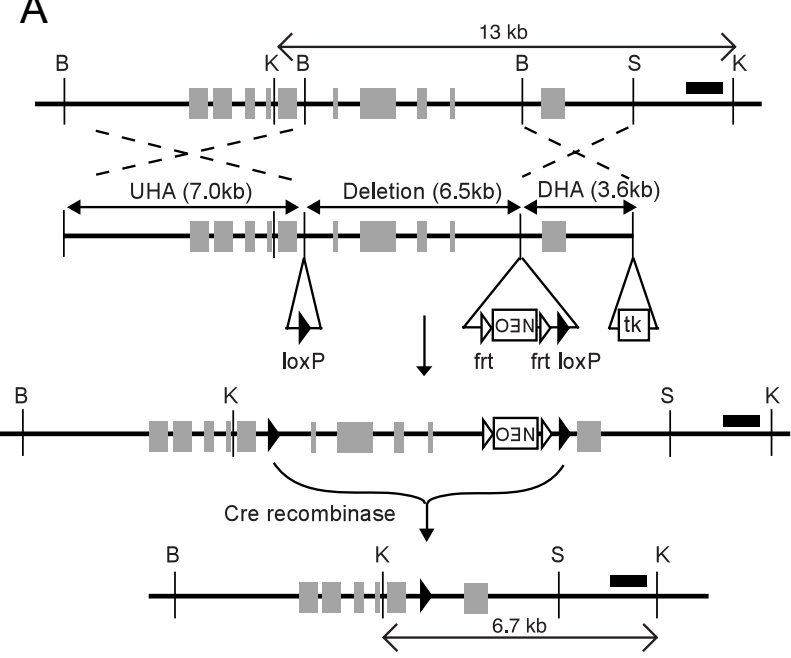

B

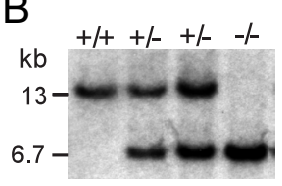

C

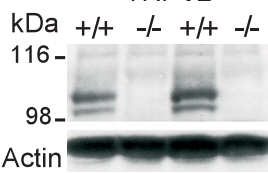

TRPV1

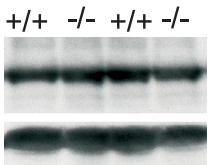

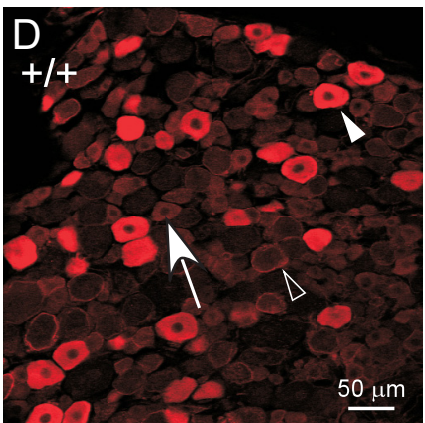

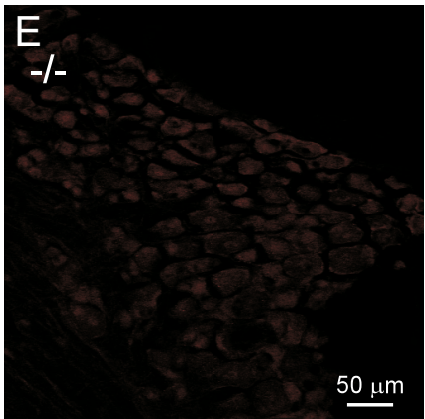

$\mathrm{F}$

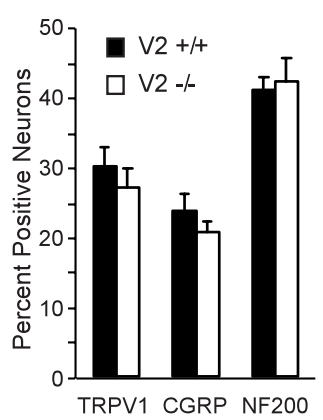

G

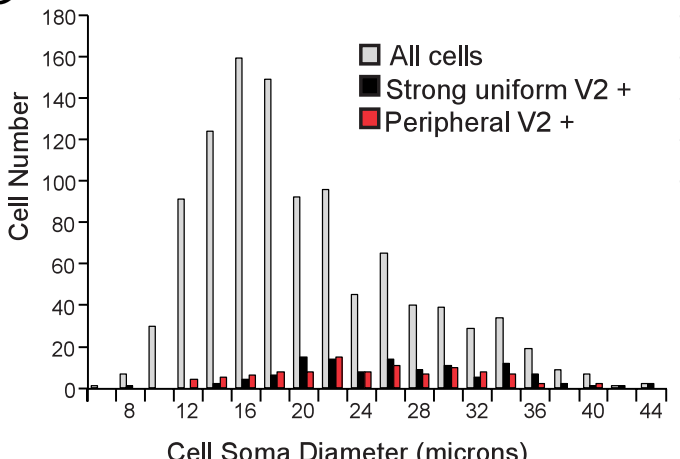

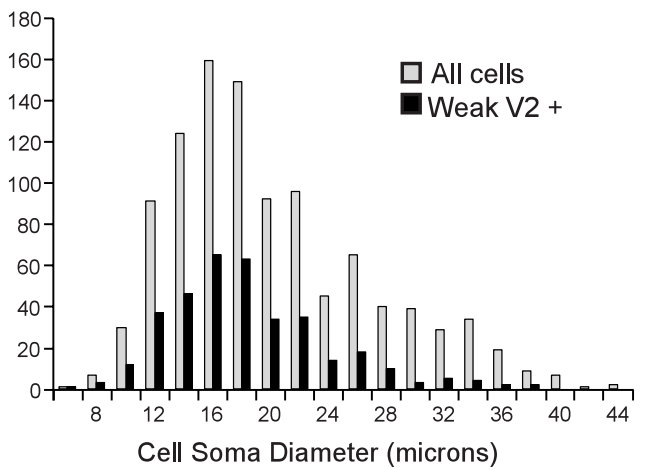

Figure 1. Generation of TRPV2 K0 mice. A, Schematic of TRPV2 K0 strategy. From the top, TRPV2 genomic locus, targeting construct, targeted TRPV2 allele, and Cre-recombined TRPV2 allele. Gray bars represent exons. Black bar represents Southern probe. B, BstEll; K, Kpnl; S, Spel; NEO, neomycin resistance cassette; tk, herpes simplex virus thymidine kinase; UHA, upstream homology arm; DHA downstream homology arm; LoxP, Cre recombination site. B, Southern blot of tail genomic DNA from mice of the indicated genotypes. WT band, $13 \mathrm{~kb}$; disrupted band, $6.7 \mathrm{~kb}$. $\boldsymbol{C}$, Immunoblot of lysates from WT and TRPV2 K0 trigeminal ganglia probed with antibodies against TRPV2, TRPV1, and $\beta$-actin. Upper band in TRPV2 blot likely indicates glycosylated form. D, E, Immunofluorescence staining of WT $(\boldsymbol{D})$ and TRPV2 KO (E) L5 dorsal root ganglia with TRPV2 antibody. Representative cells exhibiting strong, uniform staining (filled arrowhead), peripheral staining (open arrowhead), and weak uniform staining (arrow) are shown. F, Prevalence of immunostaining for TRPV1, CGRP, and neurofilament (NF200) in L5 DRGs from WT (filled bars) versus TRPV2 K0 (open bars) mice. Data shown represent mean \pm SEM from $n=3-7$ mice per genotype, with $>1000$ cells scored per mouse. G, Size histogram of L5 DRG neurons obtained from WT mice immunostained for TRPV2. In both histograms, size distribution of all cells is indicated by gray bars. Left, Strong uniformly stained cells (black bars) and peripherally stained cells (red bars) are indicated. Right, Weak uniformly stained cells (black bars) are indicated.

Analysis of skin-nerve recording data. Using a previously established reliable criterion (Koltzenburg et al., 1997; Zimmermann et al., 2009), thresholds were defined as the temperature or force that elicited the second action potential. Suprathreshold stimuli were quantified in $1 \mathrm{~s}$ bins starting from the onset of the rise of the stimulus for averaged peristimulus histograms. Total number of action potentials was counted from the onset of the stimulus for $16 \mathrm{~s}$ during the heat ramp stimulus and $21 \mathrm{~s}$ for the ramp mechanical stimuli. These time periods allowed capture of action potentials that were generated at the very end of a stimulus (Koltzenburg et al., 1997).

Statistical analysis. Unless otherwise indicated, data are presented as mean $\pm \operatorname{SEM}$ ( $n=$ number of mice in behavioral and histological studies and the number of recorded fibers in electrophysiological investigations). Statistical comparisons were performed using two-tailed unpaired or paired Student's $t$ test, $U$ test, or $\chi^{2}$ test, as appropriate, or using the specific methods indicated in the text or figure legends. von Frey filament responsiveness was fitted with a sigmoidal dose-response curve using GraphPad PRISM3 (GraphPad Software) to calculate the mean and $95 \%$ confidence intervals of the force evoking a $50 \%$ response frequency in each group.

\section{Results}

\section{Generation of TRPV2 KO mice}

To evaluate the contributions of TRPV2 to thermal and mechanical sensation and to permit future tissue-specific TRPV2 gene disruption, we adopted a Cre-loxP-based KO strategy. Two loxP sites were inserted into the intronic DNA flanking four mouse TRPV2 exons encoding the fifth transmembrane, pore loop, and sixth transmembrane domains of TRPV2 (Fig. 1A). Disruption of these segments should completely eliminate TRPV2 ion channel function and result in a frame shift downstream of the deletion site. For the current study, we analyzed only global TRPV2 gene-disrupted mice. After germ-line transmission of the floxed allele, TRPV2 loxP/+ mice were crossed with transgenic mice overexpressing Cre recombinase under the control of the CMV promoter. The resulting TRPV2 loxP/+; Cre transgenic offspring, in which one floxed TRPV2 allele was presumably recombined across most tissues, were bred with WT C57BL/6 mice to allow germ-line transmission of the disrupted TRPV2 locus and permit segregative loss of the Cre transgene. TRPV2 ${ }^{+/-}$(hetero- 

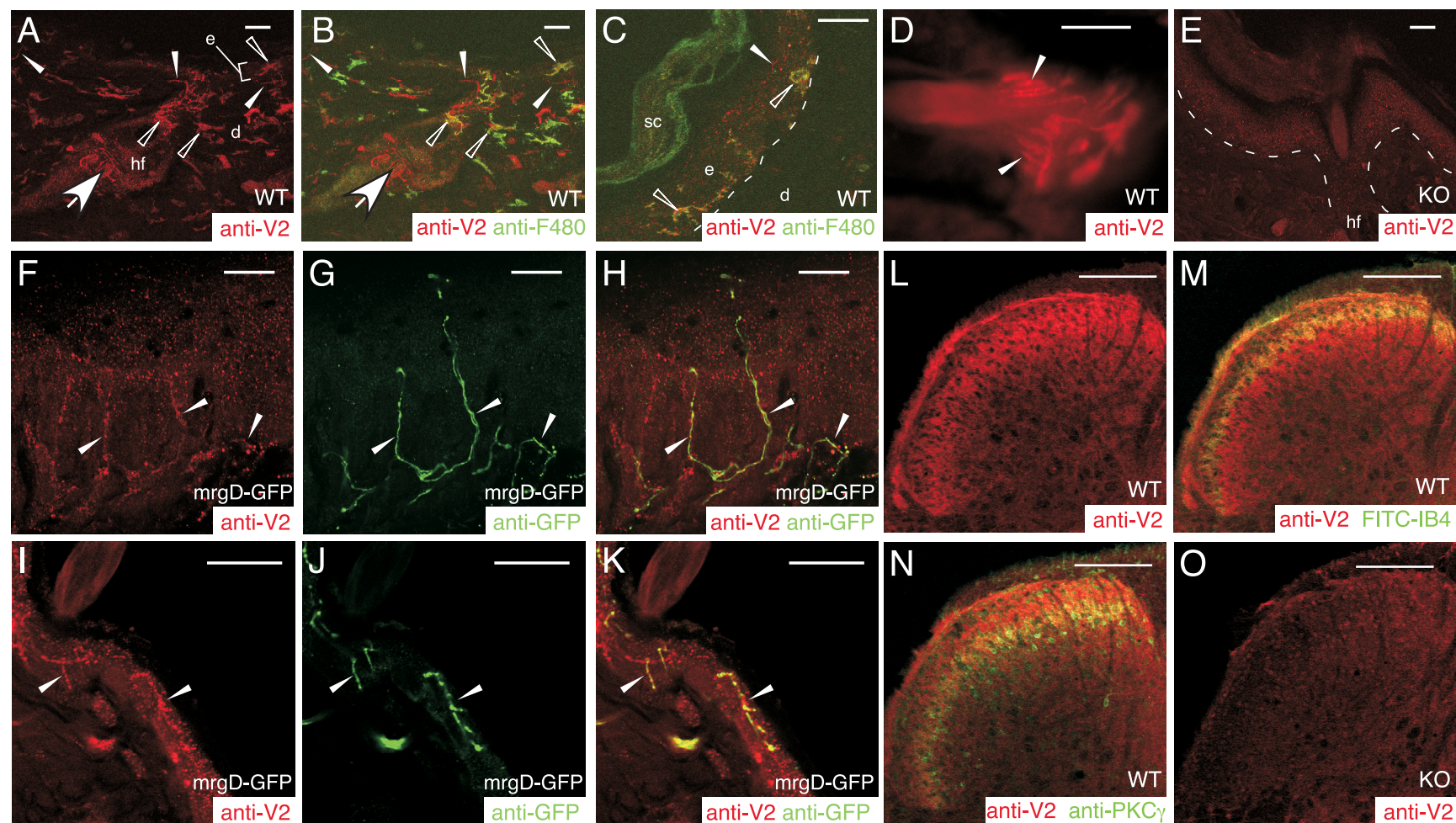

Figure 2. TRPV2 immunoreactivity in skin and spinal cord. A-C, TRPV2 immunoreactivity (red) and F4/80-immunoreactivity (green) in the hairy skin of WT mice. Open arrowheads indicate double-immunoreactive structures, and filled arrowheads indicate TRPV2-positive but F4/80-negative structures. Arrow indicates network of terminals in a hair follicle (hf). e, Epidermis; d, dermis; sc, stratum corneum. Dashed line in $\boldsymbol{C}$ denotes dermal-epidermal junction. $\boldsymbol{D}$, TRPV2 immunoreactivity in palisade endings (arrowheads) in a hair follicle. $\boldsymbol{E}$, TRPV2 antibody staining of hairy skin from TRPV2 KO mouse. Dashed lines denote dermal-epidermal junction. $\boldsymbol{F}-\boldsymbol{K}$, TRPV2 double labeling with anti-GFP in the glabrous $(\boldsymbol{F}-\boldsymbol{H})$ and hairy $(\boldsymbol{I}-\boldsymbol{K})$ skin epidermis of an mrgD-GFP mouse. Panels show TRPV2 staining (red, $\boldsymbol{F}, \boldsymbol{I}$ ), GFP staining (green, $\mathbf{G}, \boldsymbol{J}$ ), and merged image $(\boldsymbol{H}, \boldsymbol{K})$. Arrowheads indicate double-labeled epidermal fibers. $\boldsymbol{L}-\boldsymbol{N}$, Specific TRPV2 immunoreactivity in $\mathbf{L} 5$ spinal cord dorsal horn overlaps with both IB4 staining afferent projections $(\boldsymbol{M})$ and PKC $\gamma$-immunoreactive spinal cord neurons $(\boldsymbol{N})$. 0 , TRPV2 antibody staining of TRPV2 K0 spinal cord dorsal horn. Genotype and labels used are indicated in each panel. Scale bars: $\boldsymbol{A}-\boldsymbol{K}, 20 \mu \mathrm{m} ; \boldsymbol{L}-\mathbf{0}, 125 \mu \mathrm{m}$.

zygote) mice were intermated to generate TRPV2 $2^{-1-}(\mathrm{KO})$ and TRPV2 ${ }^{+/+}(\mathrm{WT})$ littermates. Genotypes were assessed using Southern blotting (Fig. $1 B$ ) and PCR (data not shown). RT-PCR confirmed the elimination of the targeted TRPV2 coding region in mRNA isolated from KO trigeminal ganglia (data not shown). PCR primers corresponding to sequences upstream of the deleted segment amplified a band of normal intensity in $\mathrm{KO}$ trigeminal ganglia, suggesting a residual mRNA product. A much weaker band was obtained using one primer upstream and one downstream of the deleted segment. Sequencing of this latter product confirmed the generation of a truncated mRNA that was out-offrame beyond the deletion and therefore unable to encode either the pore or the C-terminal portion of the channel protein. We recently reported a lack of TRPV2 function in macrophages derived from these TRPV2 KO mice (Link et al., 2010).

Immunoblot analysis confirmed the absence of detectable TRPV2 protein from lysates of TRPV2 KO trigeminal ganglia (Fig. 1C). Trigeminal ganglion expression of TRPV1 protein (Fig. 1C) was not altered by TRPV2 gene disruption. Consistent with our immunoblot findings, TRPV2-like immunofluorescence was virtually absent from TRPV2 KO trigeminal (data not shown) or dorsal root ganglia (Fig. $1 D, E$ ). In contrast, the prevalence of DRG neurons immunostained for markers of peptidergic (CGRP) or myelinated (NF200) neurons was not different between genotypes, suggesting that the absence of TRPV2 does not grossly alter sensory ganglion development (Fig. $1 F$ ).

The availability of TRPV2 KO ganglia as a definitive control for antibody specificity also allowed us to examine the WT expression pattern of TRPV2 in greater detail than was possible in previous studies, in which only strongly TRPV2-immunoreactive cell bodies ( $\sim 16 \%$ of rat DRG neurons) could be reliably scored as positive (Fig. $1 D, E$ ). We observed three classes of TRPV2immunoreactive neurons in mouse L4 and L5 dorsal root ganglion: strong immunoreactivity that was uniform across the cell body but excluded from the nucleus was observed in $9.7 \pm 0.4 \%$ of cells; strong immunoreactivity that was confined to the cell periphery was observed in $10.9 \pm 0.1 \%$ of cells; and weak, uniform immunoreactivity above the KO background was observed in $34.3 \pm 1.1 \%$ of WT cells $(n=3$ mice, $>300$ neurons scored per mouse). Size analysis revealed that strong uniformly or peripherally stained neurons tended to have medium- to large-diameter somas, whereas the weakly TRPV2-positive neurons exhibited a size distribution more closely resembling that of the general population (Fig. $1 G$ ). Together, these immunoblot and immunofluorescence findings confirm the disruption of TRPV2 protein expression in $\mathrm{KO}$ mice and provide support for reports that TRPV2 expression, although enriched in medium- to largediameter neurons, occurs in many small neurons as well (Liapi and Wood, 2005; Rutter et al., 2005; Shimosato et al., 2005).

Specific TRPV2 immunoreactivity was observed in fibers and cell bodies in the dermis and epidermis of both hairy and glabrous skin from WT mice. Much of this immunoreactivity was associated with epidermal and dermal phagocytes, which colabeled with anti-F4/80, as described (Link et al., 2010) (Fig. 2A$C)$. However, we also observed a number of fiber-like structures that were TRPV2 immunoreactive but F4/80 negative. These included subepidermal fibers (Fig. $2 A, B$ ), fibers in the interfollicular epidermis (Fig. 2C), fibers within the epidermal neck of hair 
follicles (Fig. 2A,B), and palisade endings deeper within the hair follicles (Fig. 2D). No such staining was observed in the skin of TRPV2 KO mice (Fig. 2E). To determine whether any of the TRPV2-immunoreactive epidermal fibers were neurons, we stained for TRPV2 in skin from mice expressing green fluorescent protein in a subpopulation of nonpeptidergic nociceptive neurons under the control of the mas-related gene $\mathrm{D}$ promoter (mrgD-GFP) (Zylka et al., 2005). TRPV2 staining was observed in a subset of GFP-expressing fibers in the epidermis of both glabrous (Fig. $2 \mathrm{~F}-\mathrm{H}$ ) and hairy (Fig. $2 I-\mathrm{K}$ ) skin. TRPV2 immunoreactivity was not observed in Merkel cells. Immunoreactivity in associated neurites was inconclusive (data not shown). Although TRPV2 immunoreactivity was consistently observed in Meissner's corpuscles (14 of 14) (data not shown), occasional background staining of these structures in TRPV2 null mice prevented us from establishing definitively whether these cells express TRPV2. We also examined spinal cord TRPV2 immunoreactivity. Consistent with previous reports (Caterina et al., 1999; LeWinter and Basbaum, 2004), we observed strong TRPV2 immunoreactivity in the superficial dorsal horn (Fig. $2 L-N$ ) that was absent from TRPV2 KO spinal cord (Fig. 2O). Dorsal horn TRPV2 immunoreactivity was most intense in the most superficial portion of lamina I and in a region straddling inner lamina II (labeled with IB4) (Fig. 2M) and lamina III (labeled with anti-PKC $\gamma$ ) (Fig. $2 N)$. Neither IB4 nor anti-PKC $\gamma$ staining was visibly altered in TRPV2 KO spinal cords (data not shown).

The first TRPV2 KO mice we analyzed functionally were on a randomly mixed C57BL/6 × 129S6 genetic background (see Materials and Methods). We noticed that, among the pups born to heterozygous parents on this background, there was a lowerthan-expected yield of TRPV2 KO mice (15.2\% of the total offspring genotyped at $\mathrm{P} 0,14.8 \%$ at $3-4$ weeks compared with $25 \%$ expected). The number of viable $\mathrm{KO}$ embryos was normal at E18.5, suggesting that loss of TRPV2 KO mice occurs perinatally. However, weights of $\mathrm{KO}$ embryos were significantly reduced compared with HE or WT littermates, without any gross changes in anatomy (at E18.5, WT, $1.32 \pm 0.04 \mathrm{~g}, n=4 ; \mathrm{HE}, 1.28 \pm 0.02 \mathrm{~g}$, $n=19 ; \mathrm{KO}, 1.02 \pm 0.08 \mathrm{~g}, n=8$; WT vs $\mathrm{KO}, p<0.01$; KO vs $\mathrm{HE}$, $p<0.05$, unpaired $t$ test). Reduced body weight was also observed in P0 TRPV2 KO pups (WT, $1.43 \pm 0.03 \mathrm{~g}, n=11$; KO, $1.12 \pm 0.06 \mathrm{~g}, n=8$; WT vs KO, $p<0.001$, unpaired $t$ test). No differences in lung inflation or presence of milk in the stomach were observed between genotypes at $\mathrm{P} 0$. Those $\mathrm{KO}$ mice that reached weaning age were apparently healthy, fertile, and normal in appearance, although their body weight was slightly less than that of WT littermates ( $\sim 93 \%$ of WT in males, $\sim 95 \%$ in females), during the period from weaning until 14 weeks of age $(p<0.001$, two-way ANOVA) (data not shown). After six generations backcrossing onto a more homogenous C57BL/6 background, only $2.5 \%$ of the weaning age pups born from the heterozygote parents were $\mathrm{KO}$ animals. To obtain sufficient adult mice for analysis of nociceptive function, we therefore generated most of our experimental animals either on the randomly mixed background or as F1 hybrids, obtained by mating heterozygotes backcrossed six to nine generations on a C57BL/6 background with heterozygotes backcrossed two to nine generations on a 129 S6 background. With this F1 hybrid breeding scheme, 15.5\% of pups were KOs. Body weight of surviving $\mathrm{KO}$ animals was again $\sim 7 \%$ lower in males and $\sim 5 \%$ lower in females from 2.5 to 14 weeks of age ( $p<0.001$, two-way ANOVA) (data not shown), without other obvious differences in appearance. The specific genetic background used in a given experiment is indicated either in the text or in figure legends.
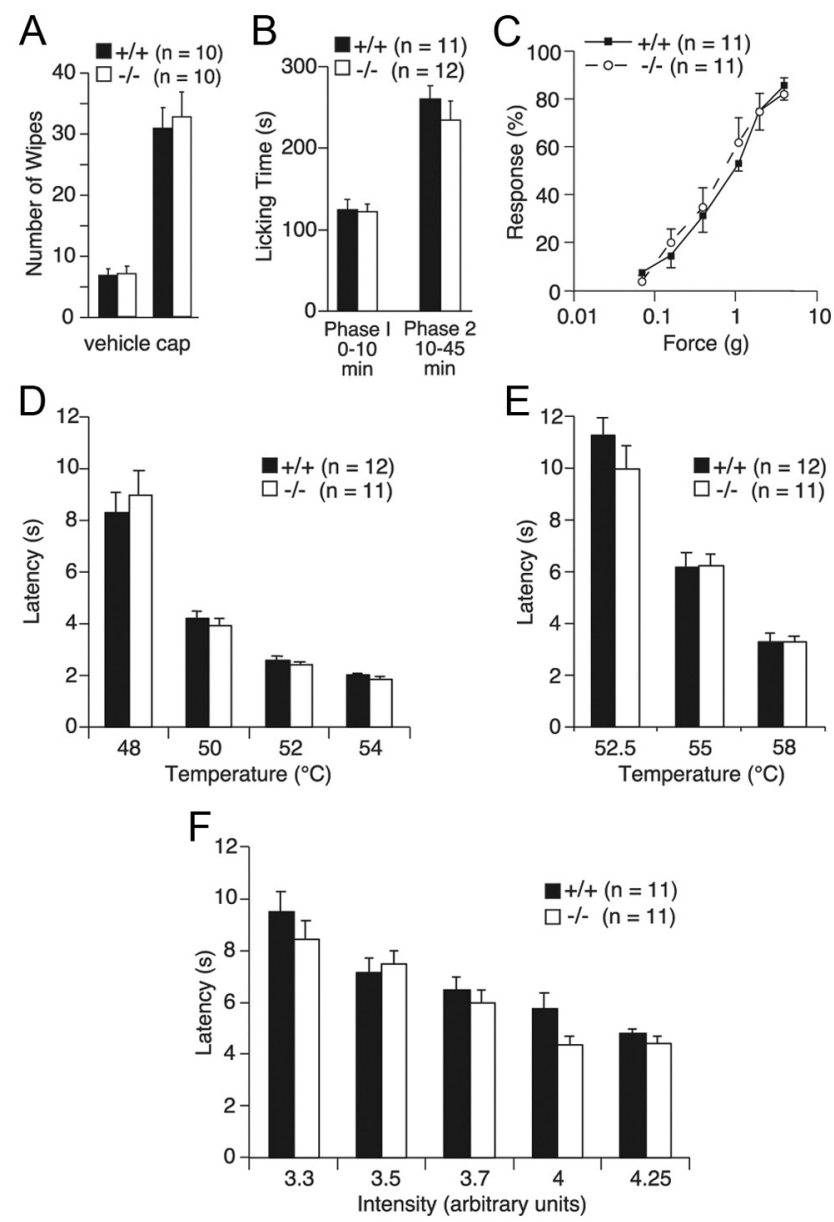

Figure 3. Acute nociception in mice lacking TRPV2. $A$, Number of eye wipes evoked over a 5 min period by application of capsaicin $(0.5 \mathrm{~mm})$ to the cornea. Mean \pm SEM $(n=10$ mice per genotype) are indicated for WT (filled bars) and TRPV2 null (open bars) mice. $\boldsymbol{B}$, Time spent licking or shaking the hindpaw after intraplantar injection of Formalin (1.2\%). Behavior was scored over the two indicated time periods and is represented as mean $\pm \mathrm{SEM}(\mathrm{WT}, n=11 ; \mathrm{KO}$, $n=12$ ). C, Mechanical sensitivity, assessed in the von Frey filament assay in WT (filled squares) and TRPV2 null (open circles) mice. Mechanical force exerted by the filaments is indicated on the $x$-axis and the percentage of challenges resulting in a response on the $y$-axis. Data shown represent mean \pm SEM ( $n=11$ per genotype). $\boldsymbol{D}, \boldsymbol{E}$, Acute thermal sensitivity measured in WT (filled bars) versus TRPV2 KO (open bars) mice, using the tail-immersion (D), hotplate $(\boldsymbol{E})$, and radiant paw-heating $(\boldsymbol{F})$ assays. Data shown represent mean \pm SEM from $n=11-12$ mice per genotype. In $\boldsymbol{F}$, lamp intensity is in arbitrary units. In the Formalin assay, mice were on the F1 hybrid background. In all other assays, mice were on the mixed background.

\section{Normal acute nociception in TRPV2 KO mice}

Acute chemical nociception was examined using capsaicin and formalin (Fig. $3 A, B$ ). In response to the application of a drop of capsaicin (0.5 mM in saline) on the corneal surface, TRPV2 KO mice showed a robust eye wipe response indistinguishable from that of WT littermates, suggesting that this channel is not required for normal TRPV1-mediated responses to capsaicin. Similarly, paw-licking behavior evoked by the injection of the TRPA1 activator formalin (1.2\%) into the hindpaw was also unaltered in mice lacking TRPV2.

Acute mechanical sensitivity was measured by stimulating the glabrous skin of the hindpaw with calibrated von Frey filaments (Fig. 3C). The resulting stimulus-response profiles were not different between genotypes, with $50 \%$ response frequency observed at $0.830 \mathrm{~g}$ for WT (95\% confidence interval 0.657-1.048 $\mathrm{g})$, and $0.709 \mathrm{~g}$ for TRPV2 KO mice ( $95 \%$ confidence interval 
0.522-0.964 g). This finding argues against a major role for TRPV2 in acute mechanical nociception.

Acute thermal nociception was evaluated using three different behavioral assays that differ in the anatomical location and geometric characteristics of the thermal stimuli, as well as in the nature of the behavioral avoidance response. In the tailimmersion assay, the distal portion of the tail is immersed in heated water, and latency to the tail flick is measured (Fig. 3D). In the hotplate assay, a mouse is place on a heated metal surface, and latency to escape behavior (jumping, hindpaw licking, or shaking) is measured (Fig. 3E). In the radiant paw-heating assay, a radiant heat source is applied to the glabrous skin of one hindpaw of a mouse standing on a glass surface, and latency of paw withdrawal response is recorded (Fig. $3 F$ ). In all the three assays, the response profile of TRPV2 KO mice was not different from that of WT littermates, over a broad range of thermal stimulus intensities. Together, these findings suggest that the thermal sensitivity of TRPV2 KO mice is not compromised in the basal state, even at temperatures above the threshold for in vitro activation of this channel.

\section{Normal inflammatory and neuropathic thermal and mechanical hyperalgesia in TRPV2 $\mathrm{KO}$ mice}

The number of TRPV2-expressing DRG neurons was reportedly increased during induction of inflammation in the rat hindpaw, suggesting the potential involvement of TRPV2 in inflammatory hyperalgesia (Shimosato et al., 2005). To address this possibility, we injected CFA $(20 \mu \mathrm{l})$ into the glabrous hindpaw skin of WT and TRPV2 KO mice on the F1 hybrid background and evaluated inflammation as well as changes in thermal and mechanical sensitivities. CFA induced strong inflammation, as evidenced by paw edema, in both genotypes (changes from the baseline, $165.4 \pm$ $4.2 \%$ for WT, $159.2 \pm 2.8 \%$ for $\mathrm{KO}$ at $24 \mathrm{~h} ; 141.9 \pm 2.4 \%$ for WT, $141.8 \pm 2.0 \%$ for $\mathrm{KO}$ at $48 \mathrm{~h} ; n=10 ; p>0.05$ for both time points, unpaired Student's $t$ test). Baseline thermal response latencies, assayed using the radiant paw-heating assay, were statistically indistinguishable between genotypes in either hindpaw (Fig. 4A) ( $p>0.05$, two-way ANOVA with Bonferroni's post hoc test), as previously observed in the mixed genetic background, although we did observe a very small difference between left and right paws in the TRPV2 KO mice in this experiment $(p<0.05)$. Regardless, mice of both genotypes exhibited comparable degrees of thermal hypersensitivity. By $1 \mathrm{~d}$ after CFA, latencies in WT mice had declined to $34.9 \pm 3.1 \%$ of baseline in the ipsilateral paw, whereas TRPV2 KO latencies had declined to $32.6 \pm 2.6 \%$ of baseline. By $2 \mathrm{~d}$, WT had partially recovered to $44.3 \pm 3.0 \%$ of baseline and TRPV2 $\mathrm{KO}$ had recovered to $43.3 \pm 3.2 \%$ of baseline (ipsilateral vs contralateral, $p<0.001$ at 1 and $2 \mathrm{~d}$ in both genotypes; WT vs KO, $p>0.05$ at 24 and $48 \mathrm{~h} ; n=10$ ). Baseline mechanical sensitivity, evaluated using the von Frey filament assay, and mechanical hypersensitivity evoked by CFA were also not significantly different between genotypes (Fig. $4 B$ ) (ipsilateral vs contralateral, $p>0.05$ at baseline and $p<0.001$ at 1 and $2 \mathrm{~d}$ in both genotypes; WT vs KO, $p>0.05$ at all time points; two-way ANOVA with Bonferroni's post hoc test). These results suggest that TRPV2 is dispensable for establishment of normal mechanical and thermal hyperalgesia during CFA inflammation.

We next asked whether TRPV2 was involved in neuropathic mechanical and thermal hypersensitivities caused by L5 spinal nerve ligation and transection, again on the F1 hybrid background. Before and after nerve injury, mechanical and thermal sensitivities were measured using the von Frey filament and radiant paw-heating assays, respectively. Baseline thermal response
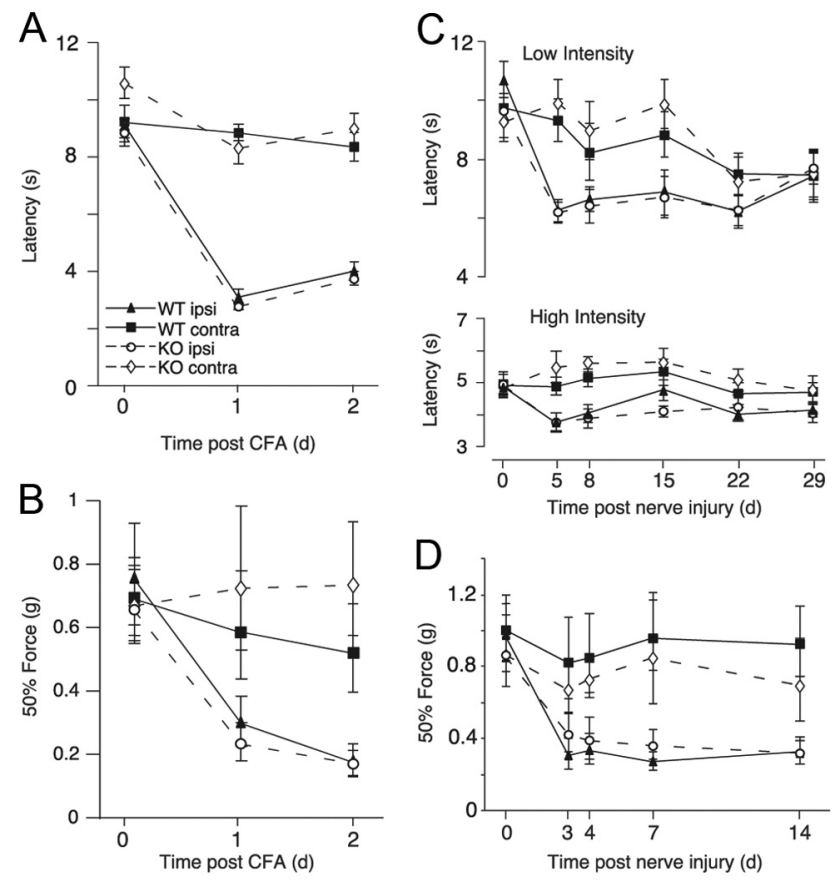

Figure 4. Thermal and mechanical hyperalgesia in mice lacking TRPV2. $A, B$, Thermal and mechanical hyperalgesia produced by intraplantar injection of (FA (20 $\mu \mathrm{l})$. Thermal sensitivity (A) was evaluated using the radiant paw-heating assay in both the injected paw (ipsilateral WT, filled triangles, solid lines; ipsilateral K0, open circles, dashed lines) and in the contralateral paw (contralateral WT, filled squares, solid lines; contralateral K0, open diamonds, dashed lines). These symbols apply to $\boldsymbol{A}-\boldsymbol{D}$. Data represent mean \pm SEM. measured at baseline or at the indicated times after CFA injection. $n=10$ mice per genotype. Mechanical sensitivity $(\boldsymbol{B})$ was evaluated in WT and TRPV2 KO mice at the indicated time points using the von Frey filament assay. Data shown represent mean $\pm 95 \%$ confidence interval of the force evoking a response on $50 \%$ of the trials. $C, D$, Thermal and mechanical hyperalgesia produced by $L 5$ spinal nerve ligation and transection. Thermal and mechanical sensitivities were evaluated as for CFA at baseline and at the indicated time points after surgery. Thermal sensitivity was evaluated at two different lamp intensities, to produce different baseline values. $n=9$ mice per genotype.

latencies were again indistinguishable between genotypes (Fig. $4 C$, top) (WT, $10.7 \pm 0.6 \mathrm{~s} ; \mathrm{KO}, 9.6 \pm 1.0 \mathrm{~s} ; n=9$ per genotype; $p>0.05$, two-way ANOVA with Bonferroni's post hoc test). Nerve injury resulted in a comparable $\sim 35 \%$ reduction in response latency in both genotypes by day 5 (ipsilateral vs contralateral: WT, $p<0.05$; KO, $p<0.01$; WT vs $\mathrm{KO}, p>0.05$ ). Beyond day 5 , the ipsilateral versus contralateral difference was significant only at day 15 in KO. WT and KO latencies did not differ significantly from one another on any day. Because TRPV2 is most robustly expressed in medium- to large-diameter myelinated neurons and because more rapid heating has been associated with selective activation of A-fiber nociceptors in rats (Yeomans and Proudfit, 1996; Tzabazis et al., 2005), we also assayed nerveinjured mice using a heat stimulus that resulted in an $\sim 5 \mathrm{~s}$ baseline latency in both WT and TRPV2 KO mice (Fig. 4C, bottom) (WT, $4.8 \pm 0.2 \mathrm{~s} ; \mathrm{KO}, 4.9 \pm 0.4 \mathrm{~s} ; n=9$ per genotype; $p>0.05$, two-way ANOVA with Bonferroni's post hoc test). After nerve damage, response latency transiently decreased by $\sim 20 \%$ in both genotypes (ipsilateral vs contralateral: WT, $p<0.001$ at day 5 and $p<0.01$ at day $8 ; \mathrm{KO}, p<0.05$ at days 8 and 18 ), but again, no significant differences between genotypes were observed at any time point. Basal mechanical sensitivity and mechanical hyperalgesia were also similar between genotypes in this experiment. By $3 \mathrm{~d}$ after injury, the force eliciting a 50\% response frequency dropped by approximately two-thirds in both genotypes and remained lower than that of the contralateral paw for at least 2 
weeks (Fig. 4D) (ipsilateral vs contralateral, $p<0.05$ to $p<0.001$ at days 3, 4, 7, and 14 ; WT vs $\mathrm{KO}, p>0.05$ at all time points; two-way ANOVA with Bonferroni's post hoc test; $n=9$ per genotype). The apparently uncompromised mechanical and thermal sensitization observed after L5 spinal nerve ligation in TRPV2 KO mice indicates that this channel is unlikely to be a major contributor to the development or maintenance of hyperalgesia in this neuropathic pain model.

\section{TRPV1 does not mask a thermosensory role for TRPV2}

One possible explanation for the lack of apparent thermal nociceptive phenotype in TRPV2 KO mice is the presence of other heat-gated channels with lower thresholds for thermal activation. We sought to eliminate the possible masking effect of TRPV1, the most prominent heat-gated channel, by generating and analyzing TRPV1/TRPV2 double $\mathrm{KO}$ mice. An additional motivation for this experiment was the potential coexpression of these channel subtypes in some neurons (Liapi and Wood, 2005; Rutter et al., 2005). Ablated expression of both TRPV1 and TRPV2 proteins in TRPV1/ TRPV2 double KO mice was confirmed by immunohistochemical staining of DRG (data not shown).

Our initial analysis was conducted on the randomly mixed background. Consistent with previous studies, TRPV1 single KO mice exhibited significantly longer withdrawal latencies to acute thermal stimuli compared with WT mice at $\geq 52.5^{\circ} \mathrm{C}$ in the hotplate assay (Fig. $5 \mathrm{~A}$ ) or at $\geq 50^{\circ} \mathrm{C}$ in the tail-immersion assay (Fig. $5 B)$. TRPV1/TRPV2 double KO mice were indistinguishable from TRPV1 single $\mathrm{KO}$ mice in the hotplate assay (Fig. $5 A$ ). On this background, we observed a slightly increased tail-immersion latency at $54^{\circ} \mathrm{C}$ and $56^{\circ} \mathrm{C}$ in the double $\mathrm{KO}$ mice compared with TRPV1 single KO mice. However, this small difference likely resulted from the variable genetic background among individual mice rather than from the absence of TRPV2 because, when we repeated this experiment on the more homogeneous F1 hybrid background, TRPV1/TRPV2 double KO mice exhibited response latencies indistinguishable from those of TRPV1 single KO mice across a range of intensities in both the tail-immersion (Fig. $5 \mathrm{C}$ ) and radiant paw-heating (Fig. 5D) assays. These results demonstrate that the lack of effect of TRPV2 gene disruption on acute thermal nociception is not attributable to masking by TRPV1.

Because TRPV1 plays a major role in inflammatory thermal hyperalgesia, we also compared inflammatory thermal sensitization by CFA between TRPV1/TRPV2 double KO mice, TRPV1 single KO mice, and WT controls on the randomly mixed background. To maximize the likelihood of observing a TRPV2-
B
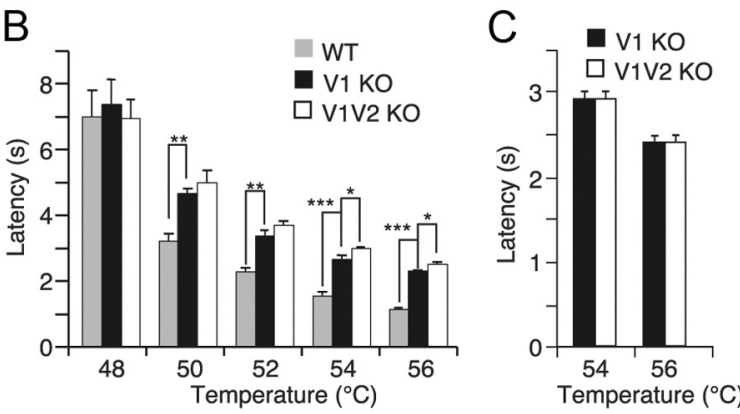

$\mathrm{E}_{5}$$$
\text { E }
$$
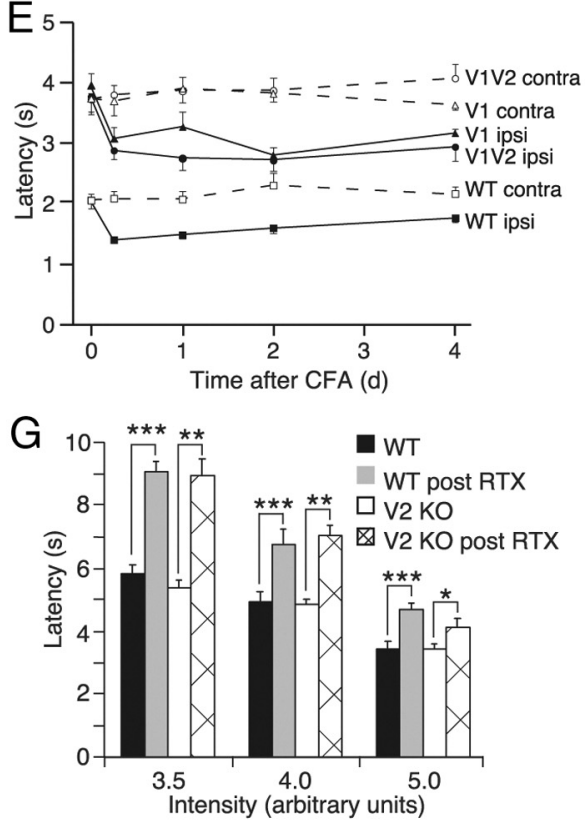

Figure 5. Thermal nociception and thermal hyperalgesia in TRPV1/TRPV2 double K0 mice or in TRPV2 K0 mice after resiniferatoxin-induced desensitization. $\boldsymbol{A}$, Baseline hotplate latencies in WT (gray bars, $n=9$ ), TRPV1 K0 (black bars, $n=11$ ), or TRPV1 K0 (black, $n=11$ ), or TRPV1/TRPV2 double KO (white, $n=9$ ) mice on the mixed background. In $\boldsymbol{A}$ and $\boldsymbol{B},{ }^{*} p<0.05$ , ${ }^{* *} p<10^{-4}$ for indicated comparisons. C, Baseline tail-immersion latency in TRPV1 K0 (black bars) versus double KO (open bars) mice on the F1 hybrid background $n=14-15$ mice per genotype. D, Baseline response 列

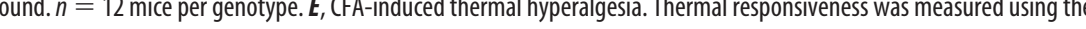
, or TRPV1/TRPV2 double K0 (circles) mice on a mixed background. Data shown represent mean $\pm S E M$ measured in the

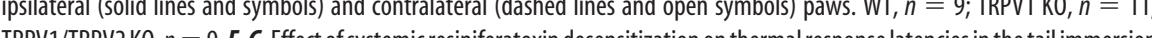
$(\boldsymbol{F})$ and radiant paw-heating $(\boldsymbol{G})$ assays in WT $(n=12)$ and TRPV2 null $(n=7)$ mice on a C57BL/6 background. Latencies were assayed before (WT, black bars; K0, white bars) or after (WT, gray bars; K0, hatched bars) subcutaneous injection of RTX into the back. Comparisons in $\boldsymbol{F}$ and $\boldsymbol{G}$ are before versus after RTX in a given genotype using paired Student's $t$ test. $\ln \boldsymbol{F},{ }^{*} p<0.001,{ }^{* *} p<$ $10^{-4},{ }^{* * *} p<10^{-5} . \operatorname{In} \mathbf{G},{ }^{*} p<0.05,{ }^{* *} p<0.01,{ }^{* * *} p<0.001$. For bar graphs, data shown represent mean \pm SEM.

mediated response, we assayed mice at high-intensity stimulus (Fig. 5E) (WT latency, $2.0 \pm 0.1 \mathrm{~s} ; n=9$ ). Under these conditions, both TRPV1 single KO mice and TRPV1/TRPV2 double KO mice exhibited a twofold longer baseline latency compared with WT, but were not different from one another (WT vs TRPV1 KO, $p<0.001$; WT vs TRPV1/TRPV2 KO, $p<0.001$; TRPV1 KO vs TRPV1/TRPV2 KO, $p>0.05$; two-way ANOVA with Bonferroni's post hoc test; WT, $n=9$; TRPV1 KO, $n=11$; TRPV1/TRPV2 KO, $n=9$ ). All three genotypes exhibited a similar reduction in withdrawal latency after CFA injection (ipsilateral vs contralateral, $p<0.0001$ in all three genotypes). Moreover, TRPV1 KO mice and TRPV1/TRPV2 KO mice were statistically indistinguishable at all times. Thus, although there 
clearly exists a TRPV1-independent component of inflammatory thermal hyperalgesia, this component does not appear to be mediated by TRPV2.

Finally, we examined the effects of functionally desensitizing neurons expressing TRPV1 using RTX, an ultrapotent TRPV1 agonist. Because RTX has been shown to cause neurotoxicity in TRPV1-expressing neurons (Szallasi and Blumberg, 1989; Neubert et al., 2003; Shimosato et al., 2005), this approach should, in theory, compromise both TRPV1-mediated thermal transduction and transduction by non-TRPV1 mechanisms in the same neurons. These experiments were conducted using a small group of WT and TRPV2 KO mice obtained at low efficiency from TRPV2 heterozygotes backcrossed six generations onto C57BL/6. As in the other backgrounds, baseline thermal sensitivities in the tail-immersion (Fig. 5F) and radiant paw-heating (Fig. 5G) assays were unaltered by the absence of TRPV2 ( $p>0.05$, unpaired $t$ test). After baseline analysis, mice were injected with RTX (10 $\mu \mathrm{g} / \mathrm{kg}$ body weight, s.c. on back) on days 1 and 7 and reassayed for thermal nociception on days 14-21. Desensitization to vanilloid compounds was confirmed by loss of capsaicin-evoked hypothermia on day 33 (data not shown). After RTX treatment, both WT and TRPV2 KO mice exhibited a significant increase in thermal response latency across a range of temperatures in both the tail-immersion and radiant paw-heating assays, consistent with desensitization of TRPV1-expressing neurons. However, the latencies were not longer in the TRPV2 KO mice than in WT mice, again strongly arguing against a role for TRPV2 in thermal nociception ( $p>0.05$, unpaired Student's $t$ test at all stimulus intensities; $n=12$ for WT, $n=7$ for KO after RTX treatment).

\section{Unimpaired responsiveness of skin afferents in TRPV2 KO} mice to noxious thermal or mechanical stimuli

Behavioral endpoints do not necessarily reflect the threshold of primary nociceptors and are suboptimal indicators of suprathreshold coding properties of afferent fibers. Furthermore, abnormal properties in one subclass of primary afferents may not lead to behavioral changes. We therefore used neurophysiological recordings as a more direct method to determine whether the functional properties of peripheral afferent sensory neurons are altered in mice lacking TRPV2. We used in vitro preparations of hairy and glabrous skin with the saphenous or tibial nerve attached to investigate single afferents innervating hairy or glabrous skin (Fig. 6). From 30 WT (12 hairy, 18 glabrous) and 19 TRPV2 KO (11 hairy, 8 glabrous) mice in the F1 hybrid background, a total of 154 single $\mathrm{A} \delta$ - or $\mathrm{C}$-fiber recordings were obtained (WT: A $\delta$-fibers, 19 hairy, 29 glabrous; C-fibers, 25 hairy, 28 glabrous; KO: A $\delta$-fibers, 13 hairy, 10 glabrous; C-fibers, 18 hairy, 12 glabrous). There was no change in the conduction velocity in any subtype of the A $\delta$ - or C-fibers (mean \pm SEM, unpaired $t$ test; A $\delta$-fibers hairy skin WT, $3.8 \pm 0.4 \mathrm{~m} / \mathrm{s}$; KO, $5.5 \pm$ $0.9 \mathrm{~m} / \mathrm{s} ; p>0.05 ; \mathrm{A} \delta$-fibers glabrous skin WT, $6.8 \pm 0.9 \mathrm{~m} / \mathrm{s} ; \mathrm{KO}$, $7.3 \pm 1.3 \mathrm{~m} / \mathrm{s} ; p>0.5$; C-fibers hairy skin WT, $0.58 \pm 0.04 \mathrm{~m} / \mathrm{s}$; $\mathrm{KO}, 0.56 \pm 0.07 \mathrm{~m} / \mathrm{s} ; p>0.3$; C-fibers glabrous skin WT, $0.55 \pm$ $0.09 \mathrm{~m} / \mathrm{s} ; \mathrm{KO}, 0.58 \pm 0.05 \mathrm{~m} / \mathrm{s} ; p>0.3)$, indicating that the absence of TRPV2 does not alter this basic biophysical property.

Because the strongest expression of TRPV2 is observed in medium- to large-sized DRG neurons, our first objective was to investigate whether heat sensitivity of A-fiber myelinated nociceptors was altered in the absence of this channel. These myelinated nociceptors were distinguished from C-fiber nociceptors and A-fiber low-threshold mechanoreceptors by their conduction velocity, von Frey filament threshold, receptive field size, and coding properties to suprathreshold stimuli (Koltzenburg et al.,
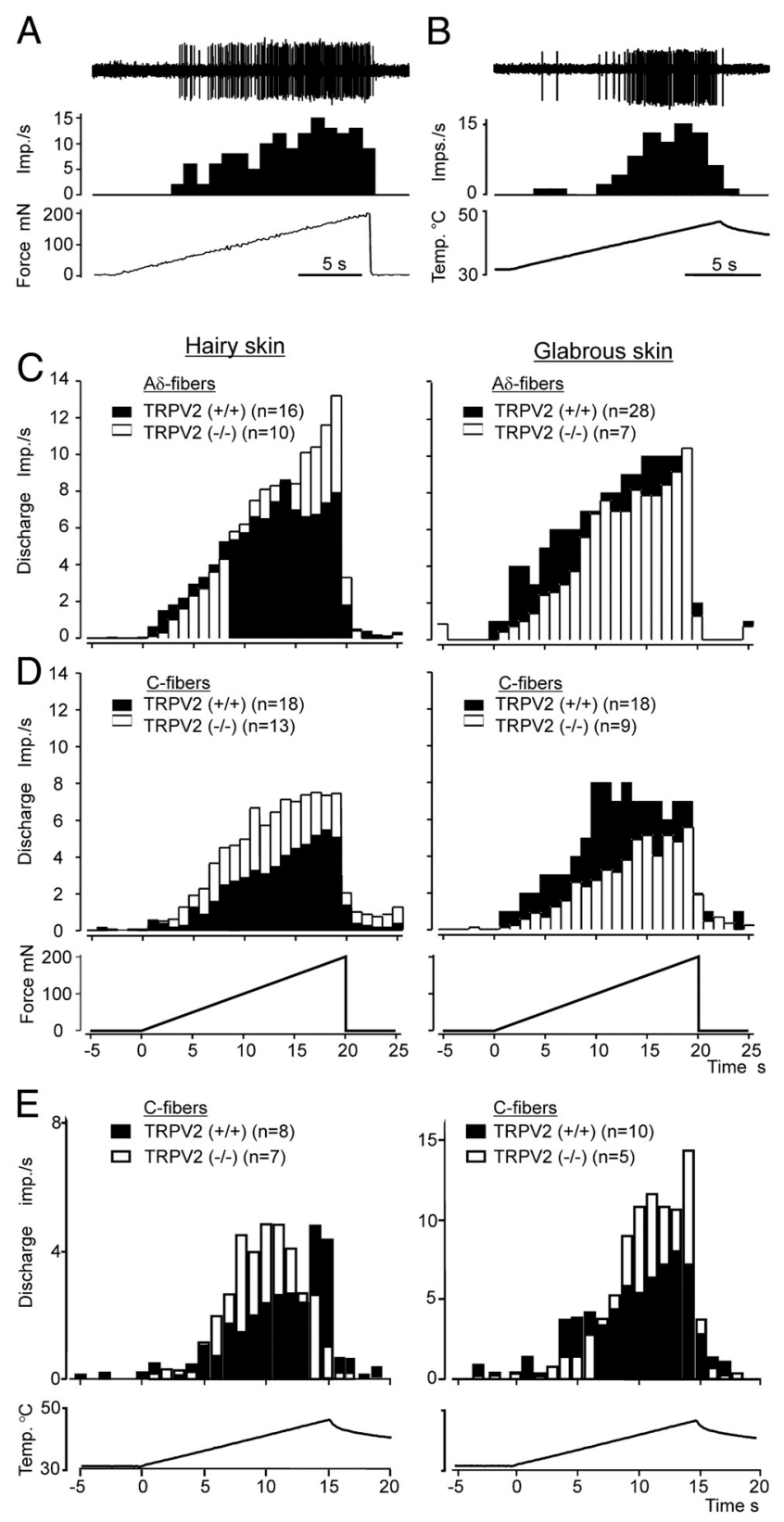

Figure 6. Sensitivity to noxious heat and mechanical stimuli are not impaired in skin-nerve preparations from mice lacking TRPV2. $A, B$, Representative examples of individual WT C-fibers innervating the hairy skin in response to a mechanical $(\boldsymbol{A})$ or heat $(\boldsymbol{B})$ ramp. $\boldsymbol{C}, \boldsymbol{D}$, Average responses of WT and TRPV2 KO A $\delta$ - $(\boldsymbol{C})$ and $(-$-fibers $(\boldsymbol{D})$ in response to the standardized mechanical ramp stimulus. $\boldsymbol{E}$, Average responses of WT and TRPV2 $\mathrm{KO} C$-fibers to the standardized heat ramp stimulus. Recordings from hairy skin are on the left, and those from glabrous skin are on the right.

1997). We initially tested mechanically sensitive A-fiber nociceptors, all conducting within the A $\delta$ range, with a standard heat ramp. Of 19 units recorded from WT hairy skin, only one responded to heat with four action potentials at a threshold of $43.0^{\circ} \mathrm{C}$, and none of the $13 \mathrm{~A} \delta$-fibers recorded from $\mathrm{KO}$ hairy skin were activated by noxious heat. Similarly, none of the $29 \mathrm{~A} \delta$ units recorded from glabrous skin in WT mice were excited by heat, and only 1 of $10 \mathrm{~A} \delta$ units recorded from $\mathrm{KO}$ mice responded with eight action potentials at a threshold of $41.7^{\circ} \mathrm{C}$. This low prevalence of heat responsiveness among $\mathrm{A} \delta$ units prevented us from making a meaningful statistical comparison of their thermal responsiveness between genotypes. In nonhuman primates, type I 
heat-sensitive A-fiber nociceptors typically have higher thermal thresholds and longer receptor utilization times compared with type II heat-sensitive A-fiber nociceptors (Meyer et al., 2005). To rule out the possibility that the low prevalence of heat sensitivity was the consequence of an insufficient stimulus intensity, we used a plateau heat stimulus of $50^{\circ} \mathrm{C}$ at the corium and up to $30 \mathrm{~s}$ duration to test $37 \mathrm{~A} \delta$-fibers that had not responded to the standard heat ramp. This plateau heat stimulus used is of sufficient intensity to differentiate type I heat-sensitive A-fiber nociceptors from heat-insensitive A-fiber nociceptors in nonhuman primate skin (Treede et al., 1998; Ringkamp et al., 2001). In hairy skin, none of the nine units from WT or eight units from mutant mice responded to heat. Similarly, in glabrous skin, none of the 12 units from WT or 8 units from KO mice was excited.

Given our observation of low-level TRPV2 expression in small-diameter unmyelinated neurons, we also investigated whether lack of TRPV2 alters their heat responsiveness. In WT hairy skin, 8 of 23 mechanosensitive $C$-fibers were excited by heat (two mechanosensitive $\mathrm{C}$-fibers were not tested for heat responsiveness), whereas 7 of 18 responded to heat in $\mathrm{KO}$ mice ( $p>0.5$, $\chi^{2}$ test). In glabrous skin, there was also no significant difference in the proportion of heat-sensitive units between WT (10 of 28) and $\mathrm{KO}$ ( 5 of 12) preparations ( $p>0.5, \chi^{2}$ test). Furthermore, there was no significant difference in the threshold between genotypes. In hairy skin, the thresholds (mean \pm SEM) were $36.9 \pm$ $1.5^{\circ} \mathrm{C}$ in the WT and $37.5 \pm 2.4^{\circ} \mathrm{C}$ in the $\mathrm{KO}(p>0.5$, unpaired $t$ test), whereas in the glabrous skin, they were $35.8 \pm 1.1^{\circ} \mathrm{C}$ in the WT and $36.0 \pm 0.8^{\circ} \mathrm{C}$ in the $\mathrm{KO}(p>0.3$, unpaired $t$ test). Inspection of the average responses to suprathreshold stimuli among heat-responsive C-fibers further showed that lack of TRPV2 did not result in a reduction of the response magnitude. There was no significant difference in the average \pm SEM total number of action potentials evoked by the standard heat ramp stimulus of C-fiber nociceptors innervating the hairy skin (WT, $27 \pm 5 ; \mathrm{KO}, 35 \pm 8 ; p>0.1$, unpaired $t$ test) or glabrous skin (WT, $64 \pm 15 ; \mathrm{KO}, 87 \pm 18 ; p>0.1$, unpaired $t$ test). There was also no significant difference in the percentage of cold-sensitive nociceptors.

Analysis of A- and C-fiber nociceptors to mechanical stimulation also revealed little change in the threshold or the response to suprathreshold stimuli. This was true for both punctate mechanical stimuli applied with calibrated von Frey filaments and suprathreshold stimuli applied with a feedback-controlled mechanical stimulator. The median (first, third quartile) of the von Frey hair threshold of A-fiber nociceptors of the hairy skin was 8 $(5.6,11.2)$ in the WT and $8(5.6,22.4)$ in the $\mathrm{KO}(p>0.5, U$ test $)$. In the glabrous skin, it was $8(5.6,16)$ in the WT and $8(8,16)$ in the $\mathrm{KO}(p>0.5, U$ test). The corresponding values for the C-fibers from hairy skin were $11.2(8,22.4)$ in the WT and $16(5.6$, $22.4)$ in the $\mathrm{KO}(p>0.5, U$ test $)$ and in glabrous skin 11.2 (5.6, $22.4)$ in the WT and $16(11.2,22.4)$ in the $\mathrm{KO}(p>0.5, U$ test $)$.

There was no significant difference in the average \pm SEM total number of action potentials evoked by the standard mechanical ramp stimulus between A-fiber nociceptors innervating the hairy skin (WT, $101 \pm 12 ; \mathrm{KO}, 118 \pm 23 ; p>0.3$, unpaired $t$ test) or glabrous skin (WT, $129 \pm 22$; KO, $106 \pm 27 ; p>0.5$, unpaired $t$ test). This also applied to C-fibers innervating the hairy skin (WT, $59 \pm 14 ; \mathrm{KO}, 83 \pm 18 ; p>0.1$, unpaired $t$ test) or glabrous skin (WT, $95 \pm 19 ; \mathrm{KO}, 52 \pm 21 ; p>0.3$, unpaired $t$ test).

In aggregate, the neurophysiological analysis of heat and mechanical sensitivity of myelinated and unmyelinated nociceptive sensory neurons from TRPV2 KO mice fully concurs with their lack of impairment in thermally and mechanically evoked nociceptive behaviors.

\section{Discussion}

Following its identification as a heat-sensitive homolog of TRPV1, TRPV2 was speculated to be another neuronal sensor of noxious heat. In contrast to this prediction, we have found that genetic ablation of TRPV2 in mice does not result in impairment of heat responsiveness, in either the basal state or under inflammatory or neuropathic conditions. Even when TRPV1 has been genetically eliminated or TRPV1-expressing neurons have been functionally compromised with RTX, the absence of TRPV2 did not impair thermal nociception over a range of temperatures in the adult mouse. Consistent with these behavioral results, the thermal responsiveness of temperature-sensitive C-fibers remained intact in skin-nerve explants from TRPV2 KO mice. Together, these findings argue against a major role for TRPV2 in mouse heat sensation.

Temperature-sensitive type I A-fibers with high thresholds, in which we most expected to observe the function of TRPV2, were not evident in skin-nerve preparations from our WT mice, despite robust TRPV2 expression among myelinated DRG neurons. This might be a consequence of the genetic background of the mice (C57BL/6 and 129S6) in the current investigation. The prevalence of heat-sensitive A-fibers appears to be much higher in BALB/C (Koltzenburg et al., 1997) or Swiss-Webster (Jeffrey Woodbury, personal communication) mice studied in vitro than in $\mathrm{C} 3 \mathrm{H} / \mathrm{HeJ}$ mice recorded in vivo (Cain et al., 2001) or in $129 \mathrm{~S}$ mice studied in vitro (Katharina Zimmermann, personal communication), yet TRPV2 expression in myelinated sensory neurons is robust even in the strains examined in our study, suggesting that TRPV2 expression is not sufficient for sensory neuron heat responsiveness.

Species differences might also contribute to this apparent discrepancy, in that type I A-fiber-like responses have been more commonly reported in rat and primate than in mouse. In dissociated rat DRG cultures, $\sim 24 \%$ of all neurons were reported to be insensitive to capsaicin and to respond to heat with a threshold of $51^{\circ} \mathrm{C}$ (Nagy and Rang, 1999). Other investigators have reported high-threshold heat-evoked responses in cultured rat DRG neurons with properties resembling those of recombinant TRPV2. Among these properties are sensitization by repeated heating, sensitization by 2-APB, a common agonist of TRPV1, TRPV2, and TRPV3, and inhibition by $\mathrm{Gd}^{3+}$. Heat-evoked currents with a threshold $>50^{\circ} \mathrm{C}$ were observed in a very small proportion (6.4\%) of DRG neurons cultured from TRPV1 null mice (Caterina et al., 2000). In another study, however, 2-APB failed to augment heat-evoked responses in DRG cultures from TRPV1 KO mice (Zimmermann et al., 2005). Moreover, robust TRPV2 immunoreactivity was not correlated with the electrophysiological responsiveness of a given sensory neuron to heat in two studies using an elegant ex vivo mouse skin-DRG-spinal cord preparation (Woodbury et al., 2004; Lawson et al., 2008). Additional evidence for potential species differences comes from the observations that, whereas rat and mouse TRPV2 can be activated by heat (Caterina et al., 1999; Chung et al., 2004b; Neeper et al., 2007) and 2-APB (Hu et al., 2004; Neeper et al., 2007), human TRPV2 apparently does not respond to either of these stimuli (Neeper et al., 2007) and from the fact that the TRPV2 sequence diverges to a greater extent among these species than does TRPV1. Our data thus argue that TRPV2 is neither necessary nor sufficient for mouse thermosensation, but we cannot exclude the possibility that this channel performs thermosensory functions in other species.

Another finding related to thermosensation was our observation of inflammatory thermal hyperalgesia in the absence of 
TRPV1, assessed with intense thermal stimuli. Although TRPV1 null mice show severely attenuated inflammatory thermal hyperalgesia, as measured at relatively low stimulus intensities, the existence of such TRPV1-independent inflammatory hyperalgesia was suggested by previous studies using RTX treatment in rats (Shimosato et al., 2005). Those responses were assumed to be mediated by TRPV2, but our data argue against this explanation. TRPV3, TRPV4, and TRP melastatin 3 (TRPM3) all apparently contribute to heat sensation, to different degrees and under different circumstances (Liedtke and Friedman, 2003; Suzuki et al., 2003; Lee et al., 2005; Moqrich et al., 2005; Huang et al., 2011; Vriens et al., 2011). However, the low thresholds of these channels and the limited or incomplete thermosensory consequences of their genetic ablation, even in concert with TRPV1 inhibition, suggest that additional transducers of intense heat remain to be identified.

Mechanical force delivered by cell stretch or hypoosmolarity is another biophysical stimulus that can activate recombinant TRPV2. It has been proposed that TRPV2 might be a component of osmo-sensing machinery in some cells (Kanzaki et al., 1999; Muraki et al., 2003) and that it is recruited to the plasma membrane in active form by cell stretch in myocytes (Iwata et al., 2003). TRPV2 has also been implicated in stretch-evoked neurite extension in DRG neurons (Shibasaki et al., 2010). In addition, TRPV2 expression was partially enriched among a subset of mechanically sensitive neurons in a mouse skin-DRG-spinal cord preparation (Lawson et al., 2008). However, we failed to observe statistically significant deficits in mechanical nociception or mechanical hyperalgesia in mice lacking TRPV2, in either behavioral or electrophysiological assays. We did observe trends toward greater mechanically evoked firing rates in hairy skin C-fibers and reduced mechanically evoked firing rates in glabrous skin C-fibers. Although these changes did not reach statistical significance, they might be indicative of minor or modulatory roles for TRPV2 in mechanosensation or neuronal excitability that fall below our level of detection. Preliminary experiments revealed no deficits in proprioception, rotarod performance, or withdrawal from gentle air-puff stimuli (our unpublished observation). Nevertheless, our observation of TRPV2 immunoreactivity in palisade endings on hair follicles suggests that more detailed examination of behavioral and physiological low-threshold mechanosensation may be warranted in the future.

It is also possible that TRPV2 acts as a sensor of nonthermal and nonmechanical stimuli in sensory neurons. 2-APB has been reported to evoke CGRP release in a TRPV2-dependent manner from rat DRG neurons stimulated with cannabinoids (Qin et al., 2008). However, no natural stimulus for TRPV2-dependent release was reported in that study. In preliminary experiments, we were unable to detect obvious differential cannabinoid-, probenecid-, or 2-APB-evoked calcium responses between WT and TRPV2 null sensory neurons in culture (our unpublished observation). However, responses to these stimuli were highly inconsistent even in our WT cultures, possibly reflecting suboptimal culture conditions for TRPV2 functional expression. Furthermore, it is clear that sensory neurons express additional targets for these chemical agents. Based on studies in other cell types (Kanzaki et al., 1999; Muraki et al., 2003; Iwata et al., 2009; Link et al., 2010), it is also possible that the localization of TRPV2 to the periphery of a subset of sensory neuronal cell bodies reflects its regulation by factors such as neurotrophins that signal through PI3 kinase pathways.

Two phenotypes that we did observe in TRPV2 KO mice were perinatal lethality and reduced adult body weight. Among TRP channels, global deletion of TRPM7 has previously been shown to completely disrupt embryonic development, though the underlying mechanisms have not yet been established (Jin et al., 2008). The reduced survival of TRPV2 KO mice was more penetrant on the C57BL/6 background than on the hybrid C57BL/6/ 12956 background. It was also associated with decreased embryo weight at E18.5. This latter finding, together with our observation of milk in the stomachs and air in the lungs of newborn TRPV2 KO mice, suggest that prenatal events, rather than postnatal failure to breathe or nurse, account for the reduced viability. TRPV2 expression is widespread. For example, in cardiac and skeletal muscle, TRPV2 has been implicated in the pathogenesis of muscular dystrophy (Iwata et al., 2003; Iwata et al., 2009). We did not observe obvious alterations in cardiac or skeletal muscle anatomy or in locomotor function in either neonatal or adult TRPV2 KO mice. However, we cannot yet exclude more subtle alterations in cardiovascular or muscular function that might account for their reduced perinatal viability. Another intriguing possibility is that the perinatal lethality of TRPV2 absence stems from its roles in immune cell function (Stokes et al., 2004; Nagasawa et al., 2007; Link et al., 2010; Yamashiro et al., 2010). It is also unclear whether the adult body weight and perinatal lethality phenotypes stem from the same defect. The fact that TRPV2 KO mouse weights remain at a relatively constant fraction of wild-type control weight during early adulthood implies that postnatal growth, per se, is not defective. Both phenotypes clearly warrant additional examination. It also remains formally possible that the negative mechanosensory and/or thermosensory phenotype of TRPV2 $\mathrm{KO}$ mice results from compensation by other mechanisms and that such compensation is strongest in those $\mathrm{KO}$ mice that survive. The acute elimination of TRPV2 function from conditional $\mathrm{KO}$ mice might allow us in the future to circumvent any such hypothetical compensatory processes.

\section{References}

Ahluwalia J, Rang H, Nagy I (2002) The putative role of vanilloid receptorlike protein-1 in mediating high threshold noxious heat-sensitivity in rat cultured primary sensory neurons. Eur J Neurosci 16:1483-1489.

Bang S, Kim KY, Yoo S, Lee SH, Hwang SW (2007) Transient receptor potential V2 expressed in sensory neurons is activated by probenecid. Neurosci Lett 425:120-125.

Cain DM, Khasabov SG, Simone DA (2001) Response properties of mechanoreceptors and nociceptors in mouse glabrous skin: an in vivo study. J Neurophysiol 85:1561-1574.

Caterina MJ, Schumacher MA, Tominaga M, Rosen TA, Levine JD, Julius D (1997) The capsaicin receptor: a heat-activated ion channel in the pain pathway. Nature 389:816-824.

Caterina MJ, Rosen TA, Tominaga M, Brake AJ, Julius D (1999) A capsaicin receptor homologue with a high threshold for noxious heat. Nature 398:436-441.

Caterina MJ, Leffler A, Malmberg AB, Martin WJ, Trafton J, Petersen-Zeitz KR, Koltzenburg M, Basbaum AI, Julius D (2000) Impaired nociception and pain sensation in mice lacking the capsaicin receptor. Science 288:306-313.

Chung MK, Lee H, Mizuno A, Suzuki M, Caterina MJ (2004b) 2 -aminonethoxydiphenyl borate activates and sensitizes the heat-gated ion channel, TRPV3. J Neurosci 24:5177-5182.

Davis JB, Gray J, Gunthorpe MJ, Hatcher JP, Davey PT, Overend P, Harries MH, Latcham J, Clapham C, Atkinson K, Hughes SA, Rance K, Grau E, Harper AJ, Pugh PL, Rogers DC, Bingham S, Randall A, Sheardown SA (2000) Vanilloid receptor-1 is essential for inflammatory thermal hyperalgesia. Nature 405:183-187.

Dubner R, Price DD, Beitel RE, Hu JW (1977) Peripheral neural correlates of behavior in monkey and human related to sensory-discriminative aspects of pain. In: Pain in the trigeminal region (Anderson DJ, Matthews B, eds), pp 57-66. Amsterdam: Elsevier.

García-Martinez C, Humet M, Planells-Cases R, Gomis A, Caprini M, Viana F, De La Pena E, Sanchez-Baeza F, Carbonell T, De Felipe C, Pérez-Paya E, 
Belmonte C, Messeguer A, Ferrer-Montiel A (2002) Attenuation of thermal nociception and hyperalgesia by VR1 blockers. Proc Natl Acad Sci USA 99:2374-2379.

Gavva NR, Tamir R, Qu Y, Klionsky L, Zhang TJ, Immke D, Wang J, Zhu D, Vanderah TW, Porreca F, Doherty EM, Norman MH, Wild KD, Bannon AW, Louis JC, Treanor JJ (2005) AMG 9810 [(E)-3-(4-t-butylphenyl)$\mathrm{N}$-(2,3-dihydrobenzo[b] [1,4] dioxin-6-yl)acrylamide], a novel vanilloid receptor 1 (TRPV1) antagonist with antihyperalgesic properties. J Pharmacol Exp Ther 313:474-484.

Guan Y, Johanek LM, Hartke TV, Shim B, Tao YX, Ringkamp M, Meyer RA, Raja SN (2008) Peripherally acting mu-opioid receptor agonist attenuates neuropathic pain in rats after L5 spinal nerve injury. Pain 138: 318-329.

Hu HZ, Gu Q, Wang C, Colton CK, Tang J, Kinoshita-Kawada M, Lee LY, Wood JD, Zhu MX (2004) 2-aminoethoxydiphenyl borate is a common activator of TRPV1, TRPV2, and TRPV3. J Biol Chem 279:35741-35748.

Huang SM, Li X, Yu Y, Wang J, Caterina MJ (2011) TRPV3 and TRPV4 ion channels are not major contributors to mouse heat sensation. Mol Pain $7: 37$.

Iwata Y, Katanosaka Y, Arai Y, Komamura K, Miyatake K, Shigekawa M (2003) A novel mechanism of myocyte degeneration involving the $\mathrm{Ca}^{2+}$ permeable growth factor-regulated channel. J Cell Biol 161:957-967.

Iwata Y, Katanosaka Y, Arai Y, Shigekawa M, Wakabayashi S (2009) Dominant-negative inhibition of $\mathrm{Ca}^{2+}$ influx via TRPV2 ameliorates muscular dystrophy in animal models. Hum Mol Genet 18:824-834.

Jin J, Desai BN, Navarro B, Donovan A, Andrews NC, Clapham DE (2008) Deletion of Trpm7 disrupts embryonic development and thymopoiesis without altering $\mathrm{Mg}^{2+}$ homeostasis. Science 322:756-760.

Juvin V, Penna A, Chemin J, Lin YL, Rassendren FA (2007) Pharmacological characterization and molecular determinants of the activation of TRPV2 channel orthologs by 2-aminoethoxydiphenyl borate. Mol Pharmacol 72:1258-1268.

Kanzaki M, Zhang YQ, Mashima H, Li L, Shibata H, Kojima I (1999) Translocation of a calcium-permeable cation channel induced by insulin-like growth factor-I. Nat Cell Biol 1:165-170.

Koltzenburg M, Stucky CL, Lewin GR (1997) Receptive properties of mouse sensory neurons innervating hairy skin. J Neurophysiol 78:1841-1850.

Lawson JJ, McIlwrath SL, Woodbury CJ, Davis BM, Koerber HR (2008) TRPV1 unlike TRPV2 is restricted to a subset of mechanically insensitive cutaneous nociceptors responding to heat. J Pain 9:298-308.

Lee H, Iida T, Mizuno A, Suzuki M, Caterina MJ (2005) Altered thermal selection behavior in mice lacking transient receptor potential vanilloid 4 . J Neurosci 25:1304-1310.

Leffler A, Linte RM, Nau C, Reeh P, Babes A (2007) A high-threshold heatactivated channel in cultured rat dorsal root ganglion neurons resembles TRPV2 and is blocked by gadolinium. Eur J Neurosci 26:12-22.

Lewinter RD, Skinner K, Julius D, Basbaum AI (2004) Immunoreactive TRPV-2 (VRL-1), a capsaicin receptor homolog, in the spinal cord of the rat. J Comp Neurol 470:400-408.

Liapi A, Wood JN (2005) Extensive co-localization and heteromultimer formation of the vanilloid receptor-like protein TRPV2 and the capsaicin receptor TRPV1 in the adult rat cerebral cortex. Eur J Neurosci 22:825-834.

Liedtke W, Friedman JM (2003) Abnormal osmotic regulation in trpv4 ${ }^{-/-}$ mice. Proc Natl Acad Sci USA 100:13698-13703.

Link TM, Park U, Vonakis BM, Raben DM, Soloski MJ, Caterina MJ (2010) TRPV2 has a pivotal role in macrophage particle binding and phagocytosis. Nat Immunol 11:232-239.

Meyer RA, Ringkamp M, Campbell JN, Raja SN (2005) Peripheral mechanisms of cutaneous nociception. In: Wall and Melzack's textbook of pain, 5th edition (McMahon SB, Koltzenburg M, eds), pp 3-34. Amsterdam: Edinburgh: Churchill Livingstone.

Moqrich A, Hwang SW, Earley TJ, Petrus MJ, Murray AN, Spencer KS, Andahazy M, Story GM, Patapoutian A (2005) Impaired thermosensation in mice lacking TRPV3, a heat and camphor sensor in the skin. Science 307:1468-1472.

Muraki K, Iwata Y, Katanosaka Y, Ito T, Ohya S, Shigekawa M, Imaizumi Y (2003) TRPV2 is a component of osmotically sensitive cation channels in murine aortic myocytes. Circ Res 93:829-838.

Nagasawa M, Nakagawa Y, Tanaka S, Kojima I (2007) Chemotactic peptide fMetLeuPhe induces translocation of the TRPV2 channel in macrophages. J Cell Physiol 210:692-702.

Nagy I, Rang H (1999) Noxious heat activates all capsaicin-sensitive and also a sub-population of capsaicin-insensitive dorsal root ganglion neurons. Neuroscience 88:995-997.

Neeper MP, Liu Y, Hutchinson TL, Wang Y, Flores CM, Qin N (2007) Activation properties of heterologously expressed mammalian TRPV2: evidence for species dependence. J Biol Chem 282:15894-15902.

Neubert JK, Karai L, Jun JH, Kim HS, Olah Z, Iadarola MJ (2003) Peripherally induced resiniferatoxin analgesia. Pain 104:219-228.

Qin N, Neeper MP, Liu Y, Hutchinson TL, Lubin ML, Flores CM (2008) TRPV2 is activated by cannabidiol and mediates CGRP release in cultured rat dorsal root ganglion neurons. J Neurosci 28:6231-6238.

Rau KK, Jiang N, Johnson RD, Cooper BY (2007) Heat sensitization in skin and muscle nociceptors expressing distinct combinations of TRPV1 and TRPV2 protein. J Neurophysiol 97:2651-2662.

Ringkamp M, Peng YB, Wu G, Hartke TV, Campbell JN, Meyer RA (2001) Capsaicin responses in heat-sensitive and heat-insensitive A-fiber nociceptors. J Neurosci 21:4460-4468.

Rutter AR, Ma QP, Leveridge M, Bonnert TP (2005) Heteromerization and colocalization of TrpV1 and TrpV2 in mammalian cell lines and rat dorsal root ganglia. Neuroreport 16:1735-1739.

Schwenk F, Baron U, Rajewsky K (1995) A cre-transgenic mouse strain for the ubiquitous deletion of loxP-flanked gene segments including deletion in germ cells. Nucleic Acids Res 23:5080-5081.

Shibasaki K, Murayama N, Ono K, Ishizaki Y, Tominaga M (2010) TRPV2 enhances axon outgrowth through its activation by membrane stretch in developing sensory and motor neurons. J Neurosci 30:4601-4612.

Shimosato G, Amaya F, Ueda M, Tanaka Y, Decosterd I, Tanaka M (2005) Peripheral inflammation induces up-regulation of TRPV2 expression in rat DRG. Pain 119:225-232.

Stokes AJ, Shimoda LM, Koblan-Huberson M, Adra CN, Turner H (2004) A TRPV2-PKA signaling module for transduction of physical stimuli in mast cells. J Exp Med 200:137-147.

Stucky CL, Koltzenburg M (1997) The low-affinity neurotrophin receptor p75 regulates the function but not the selective survival of specific subpopulations of sensory neurons. J Neurosci 17:4398-4405.

Suzuki M, Mizuno A, Kodaira K, Imai M (2003) Impaired pressure sensation in mice lacking TRPV4. J Biol Chem 278:22664-22668.

Szallasi A, Blumberg PM (1989) Resiniferatoxin, a phorbol-related diterpene, acts as an ultrapotent analog of capsaicin, the irritant constituent in red pepper. Neuroscience 30:515-520.

Treede RD, Meyer RA, Raja SN, Campbell JN (1995) Evidence for two different heat transduction mechanisms in nociceptive primary afferents innervating monkey skin. J Physiol 483:747-758.

Treede RD, Meyer RA, Campbell JN (1998) Myelinated mechanically insensitive afferents from monkey hairy skin: heat-response properties. J Neurophysiol 80:1082-1093.

Tzabazis A, Klyukinov M, Manering N, Nemenov MI, Shafer SL, Yeomans DC (2005) Differential activation of trigeminal C or Adelta nociceptors by infrared diode laser in rats: behavioral evidence. Brain Res 1037: 148-156.

Vriens J, Owsianik G, Hofmann T, Philipp SE, Stab J, Chen X, Benoit M, Xue F, Janssens A, Kerselaers S, Oberwinkler J, Vennekens R, Gudermann T, Nilius B, Voets T (2011) TRPM3 is a nociceptor channel involved in the detection of noxious heat. Neuron 70:482-494.

Woodbury CJ, Zwick M, Wang S, Lawson JJ, Caterina MJ, Koltzenburg M, Albers KM, Koerber HR, Davis BM (2004) Nociceptors lacking TRPV1 and TRPV2 have normal heat responses. J Neurosci 24:6410-6415.

Yamashiro K, Sasano T, Tojo K, Namekata I, Kurokawa J, Sawada N, Suganami T, Kamei Y, Tanaka H, Tajima N, Utsunomiya K, Ogawa Y, Furukawa T (2010) Role of transient receptor potential vanilloid 2 in LPS-induced cytokine production in macrophages. Biochemical and biophysical research communications 398:284-289.

Yeomans DC, Proudfit HK (1996) Nociceptive responses to high and low rates of noxious cutaneous heating are mediated by different nociceptors in the rat: electrophysiological evidence. Pain 68:141-150.

Zimmermann K, Leffler A, Fischer MM, Messlinger K, Nau C, Reeh PW (2005) The TRPV1/2/3 activator 2-aminoethoxydiphenyl borate sensitizes native nociceptive neurons to heat in wildtype but not TRPV1 deficient mice. Neuroscience 135:1277-1284.

Zimmermann K, Hein A, Hager U, Kaczmarek JS, Turnquist BP, Clapham DE, Reeh PW (2009) Phenotyping sensory nerve endings in vitro in the mouse. Nat Protoc 4:174-196.

Zylka MJ, Rice FL, Anderson DJ (2005) Topographically distinct epidermal nociceptive circuits revealed by axonal tracers targeted to Mrgprd. Neuron 45:17-25. 